\title{
A Joint Inspection-Based Preventive Maintenance and Spare Ordering Optimization Policy Using a Three-Stage Failure Process
}

\author{
Fei Zhao, ${ }^{1,2,3}$ Fengfeng Xie, ${ }^{2}$ Chenghua Shi, ${ }^{4}$ and Jianshe Kang $^{3}$ \\ ${ }^{1}$ School of Business Administration, Northeastern University, Shenyang 110819, China \\ ${ }^{2}$ Northeastern University at Qinhuangdao, Qinhuangdao 066004, China \\ ${ }^{3}$ Mechanical Engineering College, Shijiazhuang 050003, China \\ ${ }^{4}$ School of Economics and Management, Hebei University of Engineering, Handan 056038, China \\ Correspondence should be addressed to Chenghua Shi; chenghuashi@hebeu.edu.cn
}

Received 29 June 2017; Revised 12 October 2017; Accepted 19 October 2017; Published 22 November 2017

Academic Editor: Michele Scarpiniti

Copyright (c) 2017 Fei Zhao et al. This is an open access article distributed under the Creative Commons Attribution License, which permits unrestricted use, distribution, and reproduction in any medium, provided the original work is properly cited.

Separated decision-making for maintenance and spare ordering is unrealistic in the industry, so this paper aims to optimize them together. A joint policy of inspection-based preventive maintenance (PM) and spare ordering considering two modes of spare ordering, namely, a regular order and an emergency order, is proposed for single-unit systems using a three-stage failure process. If the system is recognized to be in the minor defective stage, the original inspection interval is shortened and a regular order is placed. However, replacement is undertaken preventively or correctively if the severe defective stage is identified or a failure occurs. Depending on the system state and the state of the regular ordered spare when replacement is needed, all possible scenarios are considered to construct optimization model $I$. The decision variables are the optimal inspection interval and the times of shortening the original inspection interval. Additionally, model $I I$ on the basis of an assumption that the spare is always ordered at time 0 is also developed. The results from a numerical example illustrated the applicability and the effectiveness of model $I$ compared to model $I I$, and the irregular inspection policy is validated to be cost-saving compared to the regular inspection policy.

\section{Introduction}

Condition-based maintenance (CBM) has been the most common used preventive maintenance policy in the practical industry [1]. With such a policy, a system can be inspected online or offline to check the deterioration state and, accordingly, some repair actions can be arranged and performed in advance to reduce the loss caused by a functional failure. Depending on whether the system state can be monitored continuously, different studies are proposed and modeled to optimize CBM policy. When the deterioration process could be determined in real time, most papers focus on the optimization of threshold levels, which are relevant to preventive replacement and corrective replacement [2-4]. However, not all plants can be checked online; therefore, inspection as a main PM program has been extensively studied and can be observed in the industry [5-7]. Based on inspectionbased PM policy, a system is checked regularly or irregularly such that the deterioration process is usually described as a discrete state space. In our study, we consider such an inspection-based PM policy. The objective of inspectionbased PM policy is often to seek for the inspection interval by minimizing the expected cost per unit time or maximizing the availability of the system. Note that an assumption that a spare used for preventive or corrective replacement is always available is shared by most previous works [8-10]. This limits the application of these studies, since the delivery time cannot be ignored in real case. Consequently, an inspection-based PM policy will be combined with spare ordering policy by considering the delivery time in this work, rather than optimizing them separately. 


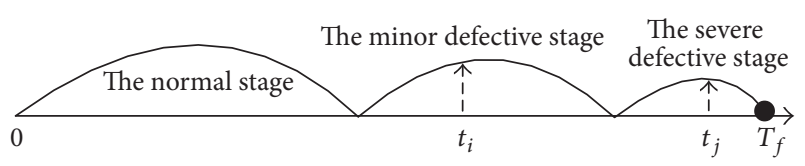

FIGURE 1: A three-stage failure process.

Some works have investigated and presented the joint optimization model of preventive maintenance policy and spare ordering policy for single-unit systems. Most of the past studies modeled the age-based replacement policy and spare provisioning policy jointly; we can refer to Osaki and Yamada [11], Sheu and Griffith [12], Jhang [13], Sheu and Chien [14], and Sheu et al. [15], Sheu et al. [16]. In the proposed models of these works, only one spare is ordered at time 0 , that is, the initial time of the system operation, and is delivered after a fixed or random lead time. Then, the system is replaced by an ordered spare at failure or at preset age $T$ whichever occurs first and the optimization models regard $T$ as a decision variable. Armstrong and Atkins $[17,18]$ extended the work of Osaki and Yamada [11] to optimize the age replacement interval $T$ and the ordering time simultaneously, and the study reported by Park and Sun [19] considered these two decision variables as well based on the work of Sheu et al. [15]. To the best of our knowledge, the study of Wang et al. [20] proposed firstly a joint policy of inspection-based PM and spare ordering; moreover, the optimization model is established and used for the determination of the optimal thresholds related to spare ordering, preventive replacement, and failure. However, it is assumed that inspections take place with a regular interval and only one kind of ordering mode is taken into account. Thus, our study will model a joint policy of inspection-based PM and spare ordering, in which inspection is carried out with an irregular interval and two modes of spare ordering subject to a regular order and an emergency order are introduced.

This paper is inspired by a plant observed from a steel industry; that is, the refractory lining of blast furnace deteriorates due to high temperature in iron and steel smelting processes such that an inspection-based PM policy is effectively utilized by engineers to prevent the occurrence of a sudden failure. Commonly, on-site personnel measure the thickness of the refractory lining with a relative longer inspection interval to judge the deterioration condition, but as the production continues the refractory lining is usually measured more frequently and preventive replacement is required. Since the refractory lining is much more expensive to purchase, managers order generally a new one at the most and it is placed when the thickness of refractory lining reaches a threshold. Motivated by this case, we treat the lifetime of a single-unit system as a three-stage failure process, which is first introduced by Wang [21] and has been widely applied to model and optimize an inspection-based policy [22, 23]. In terms of this modeling technique, the degradation process is divided into the normal stage, the minor defective stage, and the severe defective stage; thus, a state space involving four states \{normal, minor defect, severe defect, and failed\} is caused. Figure 1 gives the concept of the three-stage failure process, in which "๑" denotes a system failure. Obviously, if the system is in the normal state at the time of inspection, then inspection could be performed without any change. However, once the system is found in the minor defective stage at some inspection $t_{i}$, managers are concerned with the fact that the forthcoming failure may result in large economic losses and may sometimes even bring casualties. Therefore, a regular order is commonly placed at the time of identifying the minor defective stage $t_{i}$ and the subsequent inspections are carried out with a shortened interval to have more opportunities check the degradation state. It is noted that if inspections miss the identification of the minor defective stage, then no regular order is placed. It leads to another spare ordering mode, namely, an emergency order, but with higher cost and shorter lead time. The decision of a preventive replacement is usually made when the system is found to be in the severe defective stage by an inspection $t_{j}$. Compared with the previous literature, such a policy is expected to be able to reduce the inventory-related cost due to hold a spare. So, we present also another joint policy of inspection-based $\mathrm{PM}$ and spare ordering based on the three-stage degradation process, in which a spare is ordered at time 0 .

The contributions of this paper can be summarized as follows: (1) a joint policy of inspection-based PM and spare ordering is proposed for single-unit systems and the corresponding model is constructed to optimize the inspection policy and the spare ordering policy together; (2) the threestage failure process is introduced to describe the lifetime of the system, based on which different decisions are made depending on the system state at the time of inspection; (3) there are two modes of spare ordering in the proposed model, that is, a regular order and an emergency order; (4) the proposed policy is compared with a traditional policy in which the spare is ordered once the system begins to operate.

The remaining part of this study is organized as follows. Section 2 gives a description of the system deterioration and the joint inspection-based PM and spare ordering policy, while we formulate the optimization model in Section 3. Next, the optimization model based on the traditional policy is presented in Section 4 for comparison with that of Section 3. In Section 5, we present a numerical example and make comparison to evaluate the proposed joint policy of Section 2, and a sensitivity analysis is given. Section 6 concludes the paper.

\section{Problem Description}

2.1. The System Deterioration. Some assumptions are firstly presented and will be used in the following modeling:

(1) A single-unit system subject to a single failure mode is considered, and the lifetime process from new to a functional failure is divided into three independent stages based on the three-stage failure process, namely, normal, minor, and severe defective stages. As such, the state space \{normal, minor defect, severe defect, and failed\} can be fixed, rather than only working and failed states in most previous studies.

(2) An inspection scheme with the initial interval $t$ ( $t$ is a constant) is carried out to check which stage the 
system is in and any state can be recognized perfectly by inspections, implying perfect inspection.

(3) Do nothing and leave the system as it is when some inspection identifies the system in the normal state.

(4) If the system is found to be in the minor defective stage, shortening the inspection interval $t$ to be $t / k(k$ is an integer and larger than 1) is allowed to check the system more frequently, preventing the occurrence of a failure accordingly.

(5) If the system is found to be in the severe defective stage, replacement needs to be done immediately by a new and identical one, which is defined as an inspection replacement.

(6) Failure can be observed immediately once it arises and replacement is required to be carried out at the time of failure, which is regarded as a failure replacement.

(7) When the system is replaced, regardless of the state of the system, it is brought to a new state at which both the degradation process and the inspection process restart.

As discussed in Introduction and in the literature [2123], assumption (1) can be explained since it is closer to the reality and is often observed in the industry. Assumption (2) can be relaxed by taking consideration of imperfect inspection to identify the system state exactly with a limited probability, or a sequential inspection program, rather than a fixed inspection interval. Assumptions (3)-(7) have been proposed and used in our previous studies [22, 24]; however, the inspection interval $t$ is assumed to be halved in the work of Wang et al. [22], so we extend this assumption by changing the original inspection interval $t$ into the $1 / k$ times of $t$ after the identification of the minor defective state.

2.2. The Joint Inspection-Based PM and Spare Ordering Policy. It can be seen from assumptions (5) and (6) that a spare should be prepared in advance to perform replacement activity. However, whether the spare has been ordered or available when it is needed is a critical decision-making problem for managers. Our study assumed that the spare is placed when the system is found to be in the minor defective stage and it will be delivered after a determined lead time $l_{r}$, which is termed as the regular order. Nevertheless, the minor defective stage may be missed by inspections before a replacement is required due to identifying the severe defective stage or the appearance of a failure, which leads to no regular order being placed. In general, an emergency order is placed with a higher cost than the regular order and the spare arrives after a random lead time $l_{e}$ to do replacement. Since the spare from an emergency order is characterized by a shorter lead time, we give the lead time relationship between the regular order and the emergency order as $l_{r}>E\left(l_{e}\right)$, in which $E(u)$ returns to the expectation of a variable $u$. Besides that, if the spare resulting from the regular order has been ordered, but not on delivery, waiting for the regular ordered spare is only option, meanwhile keeping the system work or retaining the failed state without detection. There is no doubt that replacement can be conducted immediately to renew the system when the spare from the regular order has been delivered. Consequently, it can be concluded that different decisions are made in terms of the system state and the condition of the regular ordered spare, which are summarized in Table 1.

Based on all possible cases in Table 1, an optimization model by minimizing the long-run expected cost per unit time is developed and we intend to seek for the optimal solutions, that is, $t, k$. However, what we are interested in is whether the joint policy in Table 1 is preferable to the commonly used policy used in the literature, that is, placing the order when the system begins to operate. Consequently, we will make a comparison by simulations and these two policies are regarded as policy $I$ and policy II to distinguish them, and the corresponding models $I$ and $I I$ are presented in Sections 3 and 4, respectively.

\subsection{Notations}

$X_{n}(n=1,2,3)$ : Durations of three stages in the deterioration process

$f_{X_{1}}(x), f_{X_{2}}(y), f_{X_{3}}(z)$ : Probability density function (PDF) of $X_{n}$

$c_{i}$ : Cost per inspection

$c_{f}$ : Economic loss caused by a failure

$c_{p}^{w}$ : Penalty cost per unit time due to stockout, but the system is still working.

$c_{p}^{f}$ : Penalty cost per unit time due to stockout and the system is in the failed state, $c_{p}^{f}>c_{p}^{w}$

$c_{h}$ : Holding cost per unit time

$c_{R}^{r}$ : Replacement cost by a regular ordered spare

$c_{R}^{e}$ : Replacement cost by an emergency ordered spare

$l_{r}, l_{e}$ : The lead times from the regular order and the emergency order

$T_{R}$ : Replacement time for the deterioration system.

\section{Model I of the Joint Inspection-Based PM and Spare Ordering Policy}

Note that, from the problem description, two types of orders subject to the regular order and the emergency order are introduced in policy $I$, in which the regular order is placed if and only if the system is found to be in the minor defective stage and the emergency order is placed if there is no regular order. The following presents the probability expression of each case firstly, and then the objective function is given.

\subsection{The Probability Calculation}

(1) Case 1: Figure 2 shows that the system fails at $T_{f}$, $T_{f} \in\left(t_{i-1}, t_{i}\right)$, and before $T_{f}$ no inspection reveals the minor and severe defective stages, which indicates 
TABLE 1: Renewal scenarios of the joint inspection-based PM and spare ordering policy.

\begin{tabular}{|c|c|c|c|}
\hline Number & The system state & The spare state & Decision \\
\hline Case 1 & $\begin{array}{l}\text { The system deteriorates to a } \\
\text { failure at } T_{f} \text { before any } \\
\text { defective stage is identified } \\
\text { by either inspection. }\end{array}$ & The spare is not ordered. & $\begin{array}{c}\text { Place an emergency order } \\
\text { and replace the failed } \\
\text { system until the spare } \\
\text { arrives. }\end{array}$ \\
\hline Case 2 & $\begin{array}{l}\text { A failure occurs at } T_{f} \text { after } \\
\text { the minor defective stage is } \\
\text { detected. }\end{array}$ & $\begin{array}{c}\text { The spare from the regular } \\
\text { order is not on delivery at } \\
\text { the time of failure. }\end{array}$ & $\begin{array}{l}\text { Delay the replacement until } \\
\text { the arrival time of the } \\
\text { regular ordered spare. }\end{array}$ \\
\hline Case 3 & $\begin{array}{l}\text { The system fails after the } \\
\text { minor defective stage is } \\
\text { detected. }\end{array}$ & $\begin{array}{c}\text { The spare from the regular } \\
\text { order is available. }\end{array}$ & $\begin{array}{l}\text { An immediate failure } \\
\text { replacement }\end{array}$ \\
\hline Case 4 & $\begin{array}{l}\text { The severe defective stage is } \\
\text { identified by an inspection, } \\
\text { but no minor defective } \\
\text { stage is found previously. }\end{array}$ & The spare is not ordered. & $\begin{array}{l}\text { Place an emergency order, } \\
\text { keep the system work, and } \\
\text { perform replacement at the } \\
\text { arrival time of the } \\
\text { emergency ordered spare. }\end{array}$ \\
\hline Case 5 & $\begin{array}{l}\text { The severe defective stage is } \\
\text { identified by an inspection } \\
\text { after the minor defective } \\
\text { stage is found. }\end{array}$ & $\begin{array}{l}\text { The spare is ordered but } \\
\text { unavailable. }\end{array}$ & $\begin{array}{l}\text { Keep the system work and } \\
\text { delay the replacement until } \\
\text { the arrival time of the } \\
\text { regular ordered spare. }\end{array}$ \\
\hline Case 6 & $\begin{array}{l}\text { The severe defective stage is } \\
\text { identified by an inspection } \\
\text { after the minor defective } \\
\text { stage is found. }\end{array}$ & The spare is available. & $\begin{array}{l}\text { An immediate inspection } \\
\text { replacement }\end{array}$ \\
\hline
\end{tabular}

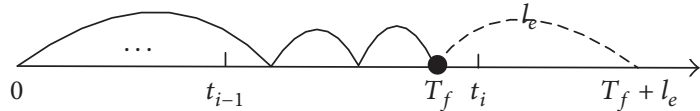

FIGURE 2: A delayed failure replacement with an emergency ordered spare.

that no regular order is heretofore placed. Thus, an emergency order is immediately placed at $T_{f}$ and the system has to be replaced until the spare arrives, which leads to a delayed failure replacement at $T_{f}+l_{e}$.

The occurrence probability of such an event can be formulated as

$$
\begin{aligned}
& P_{1}^{I}\left(t_{i-1}<T_{f}<t_{i}\right)=P\left(t_{i-1}<X_{1}<t_{i}, t_{i-1}<X_{1}+X_{2}\right. \\
& \left.\quad<t_{i}, t_{i-1}<X_{1}+X_{2}+X_{3}<t_{i}\right)=P\left(t_{i-1}<x<t_{i}, 0\right. \\
& \left.\quad<y<t_{i}-x, 0<z<t_{i}-x-y\right) \\
& \quad=\int_{t_{i-1}}^{t_{i}} \int_{0}^{t_{i}-x} \int_{0}^{t_{i}-x-y} f(x, y, z) d z d y d x,
\end{aligned}
$$

where $i=1, \ldots, \infty$ and $f(x, y, z)=f_{X_{1}}(x) \cdot f_{X_{2}}(y) \cdot f_{X_{3}}(z)$ since these three stages are assumed to be independent.

(2) Case 2: a minor defect is first found at an inspection $t_{i}$, thereby giving rise to an immediately regular order and the implementation of a shortened inspection interval scheme. As the system deteriorates seriously, a failure occurs eventually at $T_{f}$ and since the regular ordered spare has not been delivered, $T_{f}$ must not be

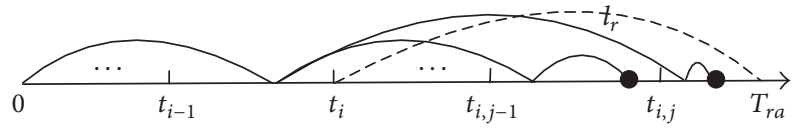

FIgURE 3: A delayed failure replacement with a regular ordered spare.

longer than the arrival time of the spare $T_{r a}\left(T_{r a}=\right.$ $t_{i}+l_{r}$ ); namely, $t_{i}<T_{f}<T_{r a}$. As shown in Figure 3, a failure replacement has to be delayed due to shortage and will be performed at $T_{r a}$ when the spare caused by the regular order is delivered.

Clearly, we can observe from Figure 3 that if there exits inspection between $t_{i}$ and $T_{r a}$, that is, $l_{r} \geq t / k$, then the failure may fall into either some inspection interval $\left(t_{i, j-1}, t_{i, j}\right)(i=$ $\left.1, \ldots, \infty ; j=1, \ldots, J ; t_{i, j-1}=t_{i}+(j-1) t / k, t_{i, j}=t_{i}+j t / k\right)$, in which $J=\operatorname{int}\left(k l_{r} / t\right)$ and $\operatorname{int}(u)$ returns to the integer part of a variable $u$. In particular, the system is also more likely to shut down in the interval $\left(t_{i, J}, T_{r a}\right)$ depending on whether there is an inspection activity at the arrival time $T_{r a}$ or not. Under this situation, we obtain the renewal probability as follows:

$$
\begin{aligned}
& P_{2}^{I}\left(t_{i}<T_{f}<T_{r a}\right)=P\left(t_{i, j-1}<T_{f}<t_{i, j}\right) \cdot I\left(l_{r}\right) \\
& \cup P\left(t_{i, J}<T_{f}<T_{r a} \mid \frac{J t}{k} \neq l_{r}\right) \cdot \delta(J)=P\left(t_{i-1}<X_{1}\right. \\
& <t_{i}, t_{i, j-1}<X_{1}+X_{2}<t_{i, j}, t_{i, j-1}<X_{1}+X_{2}+X_{3} \\
& \left.<t_{i, j}\right) \cdot I\left(l_{r}\right) \cup P\left(t_{i-1}<X_{1}<t_{i}, t_{i, J}<X_{1}+X_{2}\right.
\end{aligned}
$$




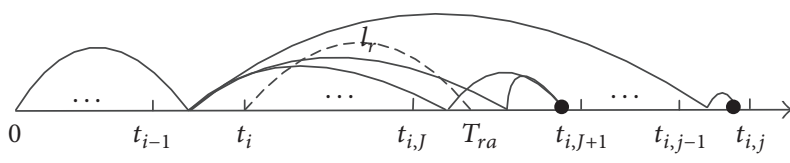

Figure 4: An immediate failure replacement with a regular ordered spare.

$$
\begin{aligned}
& \left.<T_{r a}, t_{i, J}<X_{1}+X_{2}+X_{3}<T_{r a} \mid \frac{J t}{k} \neq l_{r}\right) \cdot \delta(J) \\
& =\int_{t_{i-1}}^{t_{i}} \int_{t_{i, j-1}-x}^{t_{i, j}-x} \int_{0}^{t_{i, j}-x} f(x, y, z) d z d y d x \cdot I\left(l_{r}\right) \\
& +\int_{t_{i-1}}^{t_{i}} \int_{t_{i, j}-x}^{T_{r a}-x} \int_{0}^{T_{r a}-x} f(x, y, z) d z d y d x \cdot \delta(J) \\
& =P_{21}^{I}\left(t_{i, j-1}<T_{f}<t_{i, j}\right)+P_{22}^{I}\left(t_{i, J}<T_{f}<T_{r a}\right),
\end{aligned}
$$

where we define

$$
\begin{aligned}
& I\left(l_{r}\right)= \begin{cases}1 & l_{r} \geq \frac{t}{k} \\
0 & \text { otherwise, }\end{cases} \\
& \delta(J)= \begin{cases}1 & \frac{J t}{k} \neq l_{r} \\
0 & \frac{J t}{k}=l_{r},\end{cases}
\end{aligned}
$$

in which the condition $J t / k \neq l_{r}$ shows that no inspection takes place at $T_{r a}$. It can be seen from (2) that if there is no inspection within the interval $\left(t_{i}, T_{r a}\right)$, only the second term in (2) is computed to obtain the probability that a failure occurs in $\left(t_{i, J}, T_{r a}\right)$.

(3) Case 3: when the system fails at $T_{f}$, the spare from the regular order has been delivered and is waiting for replacement in stock, as shown in Figure 4. It can be concluded that the arrival time of the regular ordered spare must be earlier than the failure time; namely, $T_{r a}<T_{f}$. Consequently, the decision of an immediate replacement is made at the time of failure to restore the failed system to an as-good-as-new state. Similar to the derivation of (2), the failure may occur within some inspection interval,

$$
\begin{aligned}
& \left(t_{i, j-1}, t_{i, j}\right) \\
& \left(i=1, \ldots, \infty, j=J_{\text {low }}, \ldots, \infty, J_{\text {low }}=\left\{\begin{array}{ll}
J+1 & \delta(J)=0 \\
J+2 & \delta(J)=1
\end{array}\right),\right.
\end{aligned}
$$

within $\left(T_{r a}, \infty\right)$ or the interval $\left(T_{r a}, t_{i, J+1}\right)$ when the inequality $J t / k \neq l_{r}$ is satisfied.

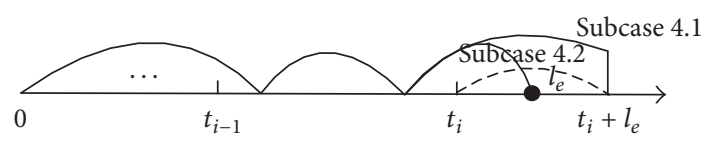

FIgURE 5: A delayed inspection replacement with an emergency ordered spare.

By summing over the above two possibilities shown in Figure 4, the probability of such an event can be constructed as

$$
\begin{aligned}
P_{3}^{I} & \left(T_{f}>T_{r a}\right)=P\left(t_{i, j-1}<T_{f}<t_{i, j}\right) \cup P\left(T_{r a}<T_{f}\right. \\
& \left.<t_{i, J+1} \mid \frac{J t}{k} \neq l_{r}\right) \cdot \delta(J)=P\left(t_{i-1}<X_{1}<t_{i}, t_{i, j-1}\right. \\
& \left.<X_{1}+X_{2}<t_{i, j}, t_{i, j-1}<X_{1}+X_{2}+X_{3}<t_{i, j}\right) \\
& +\left[P \left(t_{i-1}<X_{1}<t_{i}, t_{i, J}<X_{1}+X_{2}<T_{r a}, T_{r a}\right.\right. \\
& \left.<X_{1}+X_{2}+X_{3}<t_{i, J+1} \mid \frac{J t}{k} \neq l_{r}\right)+P\left(t_{i-1}<X_{1}\right. \\
& <t_{i}, T_{r a}<X_{1}+X_{2}<t_{i, J+1}, T_{r a}<X_{1}+X_{2}+X_{3} \\
& \left.\left.<t_{i, J+1} \mid \frac{J t}{k} \neq l_{r}\right)\right] \cdot \delta(J) \\
& =\int_{t_{i-1}}^{t_{i}} \int_{t_{i, j-1}-x}^{t_{i, j}-x} \int_{0}^{t_{i, j}-x} f(x, y, z) d z d y d x \\
& +\left[\int_{t_{i-1}}^{t_{i}} \int_{t_{i, J}-x}^{T_{r a}-x} \int_{T_{r a}-x-y}^{t_{i, J+1}-x-y} f(x, y, z) d z d y d x\right. \\
& \left.+\int_{t_{i-1}}^{t_{i}} \int_{T_{r a}-x}^{t_{i, J+1}-x} \int_{0}^{t_{i, J+1}-x-y} f(x, y, z) d z d y d x\right] \\
& \delta(J)=P_{31}^{I}\left(t_{i, j-1}<T_{f}<t_{i, j}\right)+P_{32}^{I}\left(T_{r a}<T_{f}\right.
\end{aligned}
$$

(4) Case 4: the severe defective stage is recognized by an inspection $t_{i}(i=1, \ldots, \infty)$, before which no inspection identifies the minor defective stage; therefore, it is never possible to remove the defective system with the spare from the regular order. With regard to the description in Section 2.2, an emergency order is placed immediately at the time of identifying the severe defective state and from the moment $t_{i}$ the system continues to operate as it is without inspection intervention. Once the spare from the emergency ordering is delivered, a delayed inspection replacement is performed immediately at $t_{i}+l_{e}$, as shown in Figure 5. Interestingly, two subcases 4.1 and 4.2 would arise depending on the possible states of the system at the arrival time of the emergency ordered spare, which corresponds to the severe defective state and the failed state. 


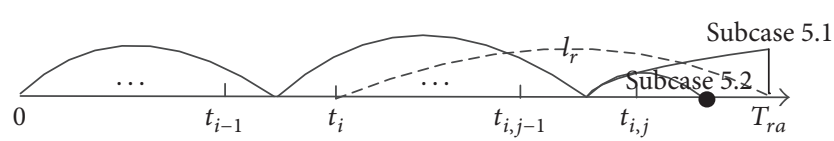

FIGURE 6: A delayed inspection replacement with a regular ordered spare.

The probabilities of two subcases in Figure 4 can be formulated as

$$
\begin{aligned}
& P_{41}^{I}\left(T_{R}=t_{i}+l_{e}\right)=P\left(t_{i-1}<X_{1}<t_{i}, t_{i-1}<X_{1}+X_{2}\right. \\
& \left.\quad<t_{i}, X_{1}+X_{2}+X_{3}>t_{i}+l_{e}, l_{e}>0\right) \\
& \quad=\int_{0}^{\infty} \int_{t_{i-1}}^{t_{i}} \int_{0}^{t_{i}-x} \int_{t_{i}+l_{e}-x-y}^{\infty} f(x, y, z) \cdot g\left(l_{e}\right) d z d y d x d l_{e}, \\
& P_{42}^{I}\left(t_{i}<T_{f}<t_{i}+l_{e}\right)=P\left(t_{i-1}<X_{1}<t_{i}, t_{i-1}<X_{1}+X_{2}\right. \\
& \left.\quad<t_{i}, t_{i}<X_{1}+X_{2}+X_{3}<t_{i}+l_{e}, l_{e}>0\right) \\
& \quad=\int_{0}^{\infty} \int_{t_{i-1}}^{t_{i}} \int_{0}^{t_{i}-x} \int_{t_{i}-x-y}^{t_{i}+l_{e}-x-y} f(x, y, z) \cdot g\left(l_{e}\right) d z d y d x d l_{e} .
\end{aligned}
$$

(5) Case 5: the minor defective stage is detected by an inspection $t_{i}$ and then the system is found to be in the severe defective stage by an inspection $t_{i, j}$; an inspection replacement is therefore required in terms of assumption (5). However, the spare from the regular order placed at $t_{i}$ has not been delivered at time of $t_{i, j}$, resulting in a delayed inspection replacement as soon as the spare is delivered. So we have the condition $t_{i, j}<T_{r a}$ to be met, which means that at least one inspection exists within the interval $\left(t_{i}, T_{r a}\right)$ and from which it is concluded that $l_{r}>t / k$ and the upper limit of index $j$ is

$$
J_{\text {upp }}= \begin{cases}J-1 & \delta(J)=0 \\ J & \delta(J)=1\end{cases}
$$

Similar to two subcases of Figure 5, there are also two different subcases depicted in Figure 6. The first subcase is that the system is still in the severe defective stage at the arrival time of the regular ordered spare and the other is that a failure may occur randomly during the waiting interval $\left(t_{i, j}, T_{r a}\right)$. Both replacements of these two subcases will take place at $T_{r a}$ whatever comes first but with different penalty costs.

Then, it is not difficult to derive the delayed renewal probabilities of two subcases 5.1 and 5.2, which are shown in (9) and (10), respectively. Evidently, the severe defective stage is longer than the arrival time of the spare from the regular order in (9); that is, $X_{1}+X_{2}+X_{3}>T_{\text {ra }}$; alternatively, the system deteriorates to a failure in $\left(t_{i, j}, T_{r a}\right)$; namely, $t_{i, j}<$ $X_{1}+X_{2}+X_{3}<T_{r a}$.

$$
\begin{aligned}
& P_{51}^{I}\left(T_{R}=T_{r a}\right)=P\left(t_{i-1}<X_{1}<t_{i}, t_{i, j-1}<X_{1}+X_{2}\right. \\
& \left.\quad<t_{i, j}, X_{1}+X_{2}+X_{3}>T_{r a}\right) \cdot I^{\prime}\left(l_{r}\right) \\
& \quad=\int_{t_{i-1}}^{t_{i}} \int_{t_{i, j-1}-x}^{t_{i, j}-x} \int_{T_{r a}-x-y}^{\infty} f(x, y, z) d z d y d x \cdot I^{\prime}\left(l_{r}\right), \\
& P_{52}^{I}\left(t_{i, j}<T_{f}<T_{r a}\right)=P\left(t_{i-1}<X_{1}<t_{i}, t_{i, j-1}<X_{1}\right. \\
& \left.+X_{2}<t_{i, j}, t_{i, j}<X_{1}+X_{2}+X_{3}<T_{r a}\right) \cdot I^{\prime}\left(l_{r}\right) \\
& =\int_{t_{i-1}}^{t_{i}} \int_{t_{i, j-1}-x}^{t_{i, j}-x} \int_{t_{i, j}-x-y}^{T_{r a}-x-y} f(x, y, z) d z d y d x \cdot I^{\prime}\left(l_{r}\right),
\end{aligned}
$$

where $i=1, \ldots, \infty ; j=1, \ldots, J_{\text {upp }}$; and we define

$$
I^{\prime}\left(l_{r}\right)= \begin{cases}1 & l_{r}>\frac{t}{k} \\ 0 & \text { otherwise }\end{cases}
$$

(6) Case 6: the spare from the regular order is in stock when the system is detected to be in the severe defective stage by an inspection $t_{i, j}$; consequently, the system can be replaced immediately by the available spare, termed as an immediate inspection renewal. This scenario indicates that the time of identifying the severe defective state crosses the arrival time of the regular ordered spare, $t_{i, j} \geq T_{r a}$, on basis of which we have the range of $j$ as

$$
j=J_{\text {low }}^{\prime}, \ldots, \infty, \quad J_{\text {low }}^{\prime}= \begin{cases}J & \delta(J)=0 \\ J+1 & \delta(J)=1\end{cases}
$$

In terms of assumption (5), note that the system has already been found to be in the minor defective stage at an inspection $t_{i}$ such that the regular ordered spare is placed and delivered for $l_{r}$ units of time for the requirement of replacing falling system, as shown in Figure 7.

Consequently, the severe defective system is replaced and renewed at $t_{i, j}$ with the probability given in the following equation:

$$
\begin{aligned}
P_{6}^{I} & \left(T_{R}=t_{i, j}\right)=P\left(t_{i-1}<X_{1}<t_{i}, t_{i, j-1}<X_{1}+X_{2}\right. \\
& \left.<t_{i, j}, X_{1}+X_{2}+X_{3}>t_{i, j}\right) \\
& =\int_{t_{i-1}}^{t_{i}} \int_{t_{i, j-1}-x}^{t_{i, j}-x} \int_{t_{i, j}-x-y}^{\infty} f(x, y, z) d z d y d x .
\end{aligned}
$$

3.2. The Model Construction. By the above analyses of the six mutually exclusive and exhaustive cases, as shown in (1), (2), (5), (6), (7), (9), (10), and (13), the expected costs caused by 
TABLE 2: Expected costs caused by the penalty time and the holding time.

\begin{tabular}{lcc}
\hline & Cost of the penalty time & Cost of the holding time \\
\hline Case 1 & $c_{p}^{f} \cdot \int_{0}^{\infty} l_{e} g\left(l_{e}\right) d l_{e} \cdot P_{1}^{I}\left(t_{i-1}<T_{f}<t_{i}\right)$ & 0 \\
Case 2 & $c_{p}^{f} \cdot\left(T_{r a}-T_{f}\right) \cdot P_{2}^{I}\left(t_{i}<T_{f}<T_{r a}\right)$ & 0 \\
Case 3 & 0 & $c_{h} \cdot\left(T_{f}-T_{r a}\right) \cdot P_{3}^{I}\left(T_{f}>T_{r a}\right)$ \\
Subcase 4.1 & $c_{p}^{w} \cdot l_{e} \cdot P_{41}^{I}\left(T_{R}=t_{i}+l_{e}\right)$ & 0 \\
Subcase 4.2 & {$\left[c_{p}^{w} \cdot\left(T_{f}-t_{i}\right)+c_{p}^{f} \cdot\left(t_{i}+l_{e}-T_{f}\right)\right] \cdot P_{42}^{I}\left(t_{i}<T_{f}<t_{i}+l_{e}\right)$} & 0 \\
Subcase 5.1 & $c_{p}^{w} \cdot\left(T_{r a}-t_{i, j}\right) \cdot P_{51}^{I}\left(T_{R}=T_{r a}\right)$ & 0 \\
Subcase 5.2 & {$\left[c_{p}^{w} \cdot\left(T_{f}-t_{i, j}\right)+c_{p}^{f} \cdot\left(T_{r a}-T_{f}\right)\right] \cdot P_{52}^{I}\left(t_{i, j}<T_{f}<T_{r a}\right)$} & 0 \\
Case 6 & 0 & $c_{h} \cdot\left(t_{i, j}-T_{r a}\right) \cdot P_{6}^{I}\left(T_{R}=t_{i, j}\right)$ \\
\hline
\end{tabular}

TABLE 3: Renewal time.

\begin{tabular}{lcc}
\hline Number & RT & Descriptions \\
Case 1 & $T_{f}+l_{e}$ & Arrival time of the emergency ordered spare \\
Case 2 & $T_{r a}\left(T_{r a}=t_{i}+l_{r}\right)$ & Arrival time of the regular ordered spare \\
Case 3 & $T_{f}$ & The failure time due to the availability of the regular ordered spare \\
Case 4 & $t_{i}+l_{e}$ & Arrival time of the emergency ordered spare \\
Case 5 & $T_{r a}\left(T_{r a}=t_{i}+l_{r}\right)$ & Arrival time of the regular ordered spare \\
Case 6 & $t_{i, j}$ & The time identifying the severe defective stage due to the available spare from the regular order
\end{tabular}

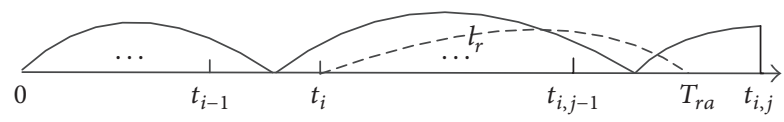

Figure 7: An immediate inspection replacement with a regular ordered spare.

the penalty time and the holding time associated in different cases are concluded in Table 2. The lead time of an emergency order $l_{e}$ is a random variable, and obviously $l_{e}$ must be a positive number, $l_{e}>0$, as we have assumed.

The cost over a renewal cycle is the sum of the inspection cost, the replacement cost, the failure cost, and the costs caused by the penalty time and the holding time. We have therefore the expected renewal cycle cost, $E_{C}^{I}(t, k)$, as follows:

$$
\begin{aligned}
& E_{C}^{I}(t, k)=\sum_{i=1}^{\infty}\left\{\left[(i-1) c_{i}+c_{f}+c_{p}^{f} \cdot \int_{0}^{\infty} l_{e} g\left(l_{e}\right) d l_{e}+c_{R}^{e}\right]\right. \\
& \cdot P_{1}^{I}\left(t_{i-1}<T_{f}<t_{i}\right) \\
& \quad+\sum_{j=0}^{J}\left[(i+j-1) c_{i}+c_{f}+c_{p}^{f} \cdot\left(T_{r a}-T_{f}\right)+c_{R}^{r}\right] \cdot P_{21}^{I}\left(t_{i, j-1}\right. \\
& \left.<T_{f}<t_{i, j}\right)+\left[(i+J) c_{i}+c_{f}+c_{p}^{f} \cdot\left(T_{r a}-T_{f}\right)+c_{R}^{r}\right] \\
& \cdot P_{22}^{I}\left(t_{i, J}<T_{f}<T_{r a}\right) \\
& +\sum_{j=J_{\mathrm{low}}}^{\infty}\left[(i+j-1) c_{i}+c_{f}+c_{h} \cdot\left(T_{f}-T_{r a}\right)+c_{R}^{r}\right] \cdot P_{31}^{I}\left(t_{i, j-1}\right. \\
& \left.<T_{f}<t_{i, j}\right)+\left[(i+J) c_{i}+c_{f}+c_{h} \cdot\left(T_{f}-T_{r a}\right)+c_{R}^{r}\right]
\end{aligned}
$$

$$
\begin{aligned}
& \cdot P_{32}^{I}\left(T_{r a}<T_{f}<t_{i, J+1}\right)+\left[i c_{i}+c_{p}^{w} \cdot l_{e}+c_{R}^{e}\right] \cdot P_{41}^{I}\left(T_{R}=t_{i}\right. \\
& \left.+l_{e}\right)+\left[i c_{i}+c_{f}+c_{p}^{w} \cdot\left(T_{f}-t_{i}\right)+c_{p}^{f} \cdot\left(t_{i}+l_{e}-T_{f}\right)+c_{R}^{e}\right] \\
& \cdot P_{42}^{I}\left(t_{i}<T_{f}<t_{i}+l_{e}\right) \\
& +\sum_{j=1}^{J_{\text {upp }}}\left[(i+j) c_{i}+c_{p}^{w} \cdot\left(T_{r a}-t_{i, j}\right)+c_{R}^{r}\right] \cdot P_{51}^{I}\left(T_{R}=T_{r a}\right) \\
& +\sum_{j=1}^{J_{\text {upp }}}\left[(i+j) c_{i}+c_{f}+c_{p}^{w} \cdot\left(T_{f}-t_{i, j}\right)+c_{p}^{f} \cdot\left(T_{r a}-T_{f}\right)+c_{R}^{r}\right] \\
& \cdot P_{52}^{I}\left(t_{i, j}<T_{f}<T_{r a}\right) \\
& \left.+\sum_{j=J_{\text {low }}^{\prime}}^{\infty}\left[(i+j) c_{i}+c_{h} \cdot\left(t_{i, j}-T_{r a}\right)+c_{R}^{r}\right] \cdot P_{6}^{I}\left(T_{R}=t_{i, j}\right)\right\} .
\end{aligned}
$$

Followed by it, Table 3 lists the renewal time (RT) of replacing the failed or severe defective system whatever it is an immediate or delayed renewal and detailed descriptions.

The expected renewal cycle length is therefore expressed as

$$
\begin{aligned}
& E_{L}^{I}(t, k)=\sum_{i=1}^{\infty}\left\{\left[T_{f}+\int_{0}^{\infty} l_{e} g\left(l_{e}\right) d l_{e}\right]\right. \\
& \cdot P_{1}^{I}\left(t_{i-1}<T_{f}<t_{i}\right)+\sum_{j=0}^{J} T_{r a} \\
& \cdot P_{21}^{I}\left(t_{i, j-1}<T_{f}<t_{i, j}\right)+T_{r a} \cdot P_{22}^{I}\left(t_{i, J}<T_{f}<T_{r a}\right)
\end{aligned}
$$


TABLE 4: All possible cases of model II.

\begin{tabular}{|c|c|c|c|}
\hline Number & The system state & The spare state & Decision \\
\hline Case 1 & \multirow{2}{*}{$\begin{array}{l}\text { The system deteriorates to a failure at } T_{f} \\
\text { before any defective stage is identified by } \\
\text { either inspection. }\end{array}$} & $\begin{array}{l}\text { The spare has not arrived by the failure } \\
\text { time. }\end{array}$ & $\begin{array}{l}\text { The system will remain failed until the } \\
\text { spare arrives. }\end{array}$ \\
\hline Case 2 & & $\begin{array}{l}\text { The spare has been delivered by the } \\
\text { failure time. }\end{array}$ & $\begin{array}{l}\text { An immediate failure replacement is } \\
\text { performed. }\end{array}$ \\
\hline Case 3 & \multirow{2}{*}{$\begin{array}{l}\text { A failure occurs at } T_{f} \text { before which the } \\
\text { minor defective stage is revealed by an } \\
\text { inspection, but the severe defective stage } \\
\text { is not found by inspections. }\end{array}$} & $\begin{array}{l}\text { The spare has not arrived by the failure } \\
\text { time. }\end{array}$ & $\begin{array}{l}\text { The system will remain failed until the } \\
\text { spare arrives. }\end{array}$ \\
\hline Case 4 & & $\begin{array}{l}\text { The spare has been delivered by the } \\
\text { failure time. }\end{array}$ & $\begin{array}{l}\text { An immediate failure replacement is } \\
\text { performed. }\end{array}$ \\
\hline Case 5 & \multirow{2}{*}{$\begin{array}{l}\text { The severe defective stage is identified by } \\
\text { an inspection, before which the minor } \\
\text { defective stage is not revealed. }\end{array}$} & $\begin{array}{l}\text { The spare has not arrived at the time of } \\
\text { identifying the severe defective stage. }\end{array}$ & $\begin{array}{l}\text { The system continues to operate and will } \\
\text { be replaced when the spare arrives. }\end{array}$ \\
\hline Case 6 & & $\begin{array}{l}\text { The spare has been delivered at the time } \\
\text { of identifying the severe defective stage. }\end{array}$ & $\begin{array}{l}\text { An immediate inspection replacement is } \\
\text { performed. }\end{array}$ \\
\hline Case 7 & \multirow{2}{*}{$\begin{array}{l}\text { The severe defective stage is identified by } \\
\text { an inspection, before which the minor } \\
\text { defective stage has been revealed. }\end{array}$} & $\begin{array}{l}\text { The spare has not arrived at the time of } \\
\text { identifying the severe defective stage. }\end{array}$ & $\begin{array}{l}\text { The system continues to operate and will } \\
\text { be replaced when the spare arrives. }\end{array}$ \\
\hline Case 8 & & $\begin{array}{l}\text { The spare has been delivered at the time } \\
\text { of identifying the severe defective stage. }\end{array}$ & $\begin{array}{l}\text { An immediate inspection replacement is } \\
\text { performed. }\end{array}$ \\
\hline
\end{tabular}

$$
\begin{aligned}
& +\sum_{j=J_{\text {low }}}^{\infty} T_{f} \cdot P_{31}^{I}\left(t_{i, j-1}<T_{f}<t_{i, j}\right)+T_{f} \\
& \cdot P_{32}^{I}\left(T_{r a}<T_{f}<t_{i, J+1}\right)+\left[t_{i}+l_{e}\right] \\
& \cdot P_{41}^{I}\left(T_{R}=t_{i}+l_{e}\right)+\left[t_{i}+l_{e}\right] \\
& \cdot P_{42}^{I}\left(t_{i}<T_{f}<t_{i}+l_{e}\right)+\sum_{j=1}^{J_{\text {upp }}} T_{r a} \cdot P_{51}^{I}\left(T_{R}=T_{r a}\right) \\
& +\sum_{j=1}^{J_{\text {upp }}} T_{r a} \cdot P_{52}^{I}\left(t_{i, j}<T_{f}<T_{r a}\right)+\sum_{j=J_{\text {low }}^{\prime}}^{\infty} t_{i, j} \\
& \left.\cdot P_{6}^{I}\left(T_{R}=t_{i, j}\right)\right\} .
\end{aligned}
$$

The component terms for various probabilities in (14) and (15) can be calculated using (1), (2), (5), (6), (7), (9), (10), and (13) and the minimization of the long-run expected cost per unit time is chosen as the objective of the proposed joint inspection-based PM and spare ordering policy and the decisions variables are the inspection interval $t$ and the value of $k$. Clearly, the system will be restored to be as good as new after each replacement. According to the renewal reward theory and on the basis of (14)-(15) [25], the long-run expected cost per unit time is equal to the ratio between the expected renewal cycle cost and the expected renewal cycle length, as shown in the following equation:

$$
\begin{aligned}
C^{I}(t, k) & =\operatorname{Lim}_{t \rightarrow \infty} \frac{\text { Total expected cost over } t}{t} \\
& =\frac{E_{C}^{I}(t, k)}{E_{L}^{I}(t, k)} .
\end{aligned}
$$

\section{Optimization Model II}

This section presents and models an integrated inspectionbased PM policy and spare ordering provisioning policy, in which an assumption that the regular order is placed when the system begins to operate, that is, the initial time " 0 ", is considered for comparison with the presented model $I$ in (16). We can conclude from this assumption that the spare must have been definitely ordered when needed; thus an emergency order due to the absence of a regular order for replenishment is not mentioned in this model. The remaining assumptions presented and used in this model can refer to assumptions of model 1, as stated in Section 2.1. Similar to the derivation of (16), we formulate the optimization model that minimizes the long-run expected cost per unit time to determine the optimal inspection interval $t$ and the value of $k$. The eight mutually exclusive and exhaustive cases given below depending on the system state and the regular ordered spare state, shown in Table 4, will be described to calculate the corresponding probabilities.

(1) Cases 1 and 2 are described by Figures 8(a) and 8 (b), respectively, from which we can observe that the deterioration process of the system may start to enter the minor defective stage after an inspection $t_{i-1}$ and the system breaks down before an inspection $t_{i}$. Obviously, note that there are different values of $i$ to calculate the probabilities of cases 1 and 2 that a failure falls in the interval $\left(t_{i-1}, t_{i}\right)$. However, the situation that a failure occurs in $\left(\underline{L}, l_{r}\right)$ should be also considered to sum up the probability of case 1 if the condition $\underline{L} \neq l_{r}$ is satisfied, in which $\underline{L}=L t$ and $L=\operatorname{int}\left(\overline{l_{r}} / t\right)$. Similarly, the system may fail in $\left(l_{r}, \bar{L}\right)(\bar{L}=(L+1) t)$ such that there is an immediate failure replacement at the occurrence time of a failure, which is shown in Figure 8(b).

Then, we obtain the probability of case 1 , which is constructed as

$$
\begin{gathered}
P_{1}^{I I}\left(T_{f}<l_{r}\right)=P\left(t_{i-1}<T_{f}<t_{i}\right) \cup P\left(\underline{L}<T_{f}<l_{r} \mid \underline{L}\right. \\
\left.\quad \neq l_{r}\right) \cdot v\left(l_{r}\right)=P\left(t_{i-1}<X_{1}<t_{i}, t_{i-1}<X_{1}+X_{2}\right.
\end{gathered}
$$




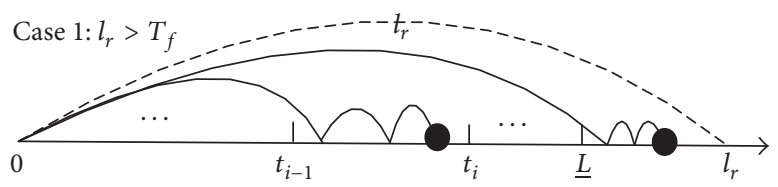

(a)

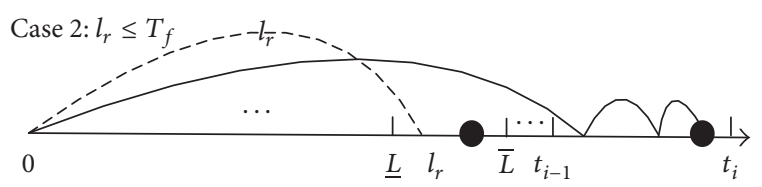

(b)

FIGURE 8: A failure replacement before either defective stage is identified.

$\left.<t_{i}, t_{i-1}<X_{1}+X_{2}+X_{3}<t_{i}\right)+P\left(\underline{L}<X_{1}<l_{r}, \underline{L}\right.$

$\left.<X_{1}+X_{2}<l_{r}, \underline{L}<X_{1}+X_{2}+X_{3}<l_{r}\right) \cdot v\left(l_{r}\right)$

$=\int_{t_{i-1}}^{t_{i}} \int_{0}^{t_{i}-x} \int_{0}^{t_{i}-x-y} f(x, y, z) d z d y d x$

$+\int_{\underline{L}}^{l_{r}} \int_{0}^{l_{r}-x} \int_{0}^{l_{r}-x-y} f(x, y, z) d z d y d x \cdot v\left(l_{r}\right)$

$=P_{11}^{I I}\left(t_{i-1}<T_{f}<t_{i}\right)+P_{12}^{I I}\left(\underline{L}<T_{f}<l_{r}\right)$,

in which $i=1, \ldots, L$ and we define the function

$$
v\left(l_{r}\right)= \begin{cases}0 & \underline{L}=l_{r} \\ 1 & \underline{L} \neq l_{r} .\end{cases}
$$

In a similar way, the probability of case 2 shown in Figure 8(b) is calculated as

$$
\begin{aligned}
P_{2}^{I I} & \left(T_{f} \geq l_{r}\right)=P\left(l_{r}<T_{f}<\bar{L} \mid \underline{L} \neq l_{r}\right) \cdot v\left(l_{r}\right) \\
& \cup P\left(t_{i-1}<T_{f}<t_{i}\right)=\left[P \left(\underline{L}<X_{1}<l_{r}, \underline{L}<X_{1}\right.\right. \\
& \left.+X_{2}<l_{r}, l_{r}<X_{1}+X_{2}+X_{3}<\bar{L}\right)+P\left(\underline{L}<X_{1}\right. \\
& \left.<l_{r}, l_{r}<X_{1}+X_{2}<\bar{L}, l_{r}<X_{1}+X_{2}+X_{3}<\bar{L}\right) \\
& +P\left(l_{r}<X_{1}<\bar{L}, l_{r}<X_{1}+X_{2}<\bar{L}, l_{r}<X_{1}+X_{2}\right. \\
& \left.\left.+X_{3}<\bar{L}\right)\right] \cdot v\left(l_{r}\right)+P\left(t_{i-1}<X_{1}<t_{i}, t_{i-1}<X_{1}\right. \\
& \left.+X_{2}<t_{i}, t_{i-1}<X_{1}+X X_{2}+X_{3}<t_{i}\right) \\
& =\left[\int_{\underline{L}}^{l_{r}} \int_{0}^{l_{r}-x} \int_{l_{r}-x-y}^{\bar{L}-x-y} f(x, y, z) d z d y d x\right. \\
& +\int_{\underline{L}}^{l_{r}} \int_{l_{r}-x}^{\bar{L}-x} \int_{0}^{\bar{L}-x-y} f(x, y, z) d z d y d x \\
& \left.+\int_{l_{r}}^{\bar{L}} \int_{0}^{\bar{L}-x} \int_{0}^{\bar{L}-x-y} f(x, y, z) d z d y d x\right] \cdot v\left(l_{r}\right) \\
& +\int_{t_{i-1}}^{t_{i}} \int_{0}^{t_{i}-x} \int_{0}^{t_{i}-x-y} f(x, y, z) d z d y d x=P_{21}^{I I}\left(l_{r}\right. \\
+ & \bar{L})+P_{22}^{I I}\left(t_{i-1}<T_{f}<t_{i}\right),
\end{aligned}
$$

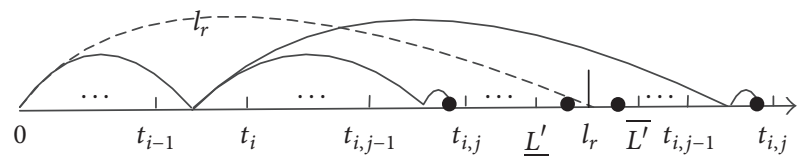

FIGURE 9: A failure replacement before only minor defective stage is identified.

in which

$$
i=I, \ldots, \infty, \quad I= \begin{cases}L+1 & v\left(l_{r}\right)=0 \\ L+2 & v\left(l_{r}\right)=1\end{cases}
$$

and the first term corresponds to the probability that the occurrence of a failure is in $\left(l_{r}, \bar{L}\right)$ but with different durations for three stages in the deterioration process.

(2) Figure 9 depicts that the system fails after the minor defective stage has been identified but before which the severe defective stage is not revealed. Depending on whether the ordered spare is delivered at the time of failure $T_{f}$, we can observe from Figure 9 that there are two types of scenario, that is, $T_{f}<l_{r}$ and $T_{f}>$ $l_{r}$, which represent cases 3 and 4 , respectively. More importantly, $T_{f} \in\left(\underline{L^{\prime}}, l_{r}\right)$ and $\left(l_{r}, \overline{L^{\prime}}\right)$ need to be taken into consideration when the condition $J_{\max }=\left(l_{r}-\right.$ $\left.t_{i}\right) /(t / k)\left(J_{\max }=\operatorname{int}\left(\left(l_{r}-t_{i}\right) /(t / k)\right)\right)$ is invalid, in which $\underline{L^{\prime}}=t_{i}+k J_{\max } / t$ and $\overline{L^{\prime}}=t_{i}+k\left(J_{\max }+1\right) / t$.

Therefore, the probability of case 3 can be formulated as

$$
\begin{aligned}
P_{3}^{I I} & \left(T_{f}<l_{r}\right)=P\left(t_{i, j-1}<T_{f}<t_{i, j}\right) \cdot \eta\left(l_{r}\right) \cup P\left(\underline{L^{\prime}}\right. \\
& \left.<T_{f}<l_{r} \mid J_{\max } \neq \frac{l_{r}-t_{i}}{t / k}\right) \cdot v^{\prime}\left(l_{r}\right)=P\left(t_{i-1}<X_{1}\right. \\
& <t_{i}, t_{i, j-1}<X_{1}+X_{2}<t_{i, j}, t_{i, j-1}<X_{1}+X_{2}+X_{3} \\
& \left.<t_{i, j}\right) \cdot \eta\left(l_{r}\right)+P\left(t_{i-1}<X_{1}<t_{i}, \underline{L^{\prime}}<X_{1}+X_{2}\right. \\
& \left.<l_{r}, \underline{L^{\prime}}<X_{1}+X_{2}+X_{3}<l_{r}\right) \cdot v^{\prime}\left(l_{r}\right) \\
& =\int_{t_{i-1}}^{t_{i}} \int_{t_{i, j-1}-x}^{t_{i, j}-x} \int_{0}^{t_{i, j}-x-y} f(x, y, z) d z d y d x \cdot \eta\left(l_{r}\right) \\
+ & \int_{t_{i-1}}^{t_{i}} \int_{\underline{L}^{\prime}-x}^{l_{r}-x} \int_{0}^{l_{r}-x-y} f(x, y, z) d z d y d x \cdot v^{\prime}\left(l_{r}\right) \\
& =P_{31}^{I I}\left(t_{i, j-1}<T_{f}<t_{i, j}\right)+P_{32}^{I I}\left(\underline{L^{\prime}}<T_{f}<l_{r}\right),
\end{aligned}
$$


in which

$$
\begin{aligned}
i & =1, \ldots, I_{\text {upp }}, \quad I_{\text {upp }}= \begin{cases}L-1 & v\left(l_{r}\right)=0 \\
L & v\left(l_{r}\right)=1,\end{cases} \\
j & =1, \ldots, J_{\max } \quad\left(J_{\max } \geq 1\right), \\
\eta\left(l_{r}\right) & = \begin{cases}0 & l_{r}-t_{i}<\frac{t}{k} \\
1 & l_{r}-t_{i} \geq \frac{t}{k},\end{cases} \\
v^{\prime}\left(l_{r}\right) & = \begin{cases}0 & J_{\max }=\frac{l_{r}-t_{i}}{t / k} \\
1 & J_{\max } \neq \frac{l_{r}-t_{i}}{t / k} .\end{cases}
\end{aligned}
$$

Furthermore, the above case 4 arises with the probability

$$
\begin{aligned}
& P_{4}^{I I}\left(T_{f}>l_{r}\right)=P\left(l_{r}<T_{f}<\overline{L^{\prime}} \mid J_{\max } \neq \frac{l_{r}-t_{i}}{t / k}\right) \\
& \cdot v^{\prime}\left(l_{r}\right) \cup P\left(t_{i, j-1}<T_{f}<t_{i, j}\right)=\left[P \left(t_{i-1}<X_{1}\right.\right. \\
& \left.\quad<t_{i}, \underline{L^{\prime}}<X_{1}+X_{2}<l_{r}, l_{r}<X_{1}+X_{2}+X_{3}<\overline{L^{\prime}}\right) \\
& +P\left(t_{i-1}<X_{1}<t_{i}, l_{r}<X_{1}+X_{2}<\overline{L^{\prime}}, l_{r}<X_{1}\right. \\
& \left.\left.+X_{2}+X_{3}<\overline{L^{\prime}}\right)\right] \cdot v^{\prime}\left(l_{r}\right)+P\left(t_{i-1}<X_{1}<t_{i}, t_{i, j-1}\right. \\
& \left.\quad<X_{1}+X_{2}<t_{i, j}, t_{i, j-1}<X_{1}+X_{2}+X_{3}<t_{i, j}\right) \\
& =\left[\int_{t_{i-1}}^{t_{i}} \int_{\overline{L^{\prime}}-x}^{l_{r}-x} \int_{l_{r}-x-y}^{\overline{L^{\prime}}-x-y} f(x, y, z) d z d y d x\right. \\
& \left.+\int_{t_{i-1}}^{t_{i}} \int_{l_{r}-x}^{\overline{L^{\prime}}-x} \int_{0}^{\overline{L^{\prime}}-x-y} f(x, y, z) d z d y d x\right] \cdot v^{\prime}\left(l_{r}\right) \\
& +\int_{t_{i-1}}^{t_{i}} \int_{t_{i, j-1}-x}^{t_{i, j}-x} \int_{0}^{t_{i, j}-x-y} f(x, y, z) d z d y d x \\
& =P_{41}^{I I}\left(l_{r}<T_{f}<\overline{L^{\prime}}\right)+P_{42}^{I I}\left(t_{i, j-1}<T_{f}<t_{i, j}\right),
\end{aligned}
$$

where we impose range restriction on the first term of (23) as $i=1, \ldots, I_{\text {upp }}$; and with regard to the second term, $i=$ $1, \ldots, \infty$,

$$
\begin{gathered}
J_{\text {Low }}= \begin{cases}1 & l_{r} \leq t_{i} \\
\rho\left(J_{\text {max }}\right) & l_{r}>t_{i},\end{cases} \\
\rho\left(J_{\text {max }}\right)= \begin{cases}J_{\text {max }}+1 & v^{\prime}\left(l_{r}\right)=0 \\
J_{\text {max }}+2 & v^{\prime}\left(l_{r}\right)=1 .\end{cases}
\end{gathered}
$$

(3) As illustrated by Figure 10, the severe defective stage is first identified at $t_{i}$ before which no inspection reveals the minor defective stage. Considering that the spare is unavailable at $t_{i}$, the system will continue to operate

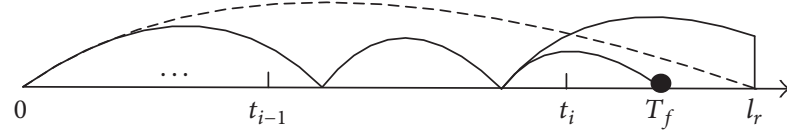

FIGURE 10: A postponed inspection replacement before which the minor defective stage is not detected.

and will be replaced by the arrival time of the spare, that is, $l_{r}$. This scenario is exactly as described in case 5. Note that the system may be either in the severe defective stage at $l_{r}$ or in the failed state, which occur with various probabilities, and we denote them by $P_{51}^{I I}\left(T_{R}=l_{r}\right)$ and $P_{52}^{I I}\left(T_{R}=l_{r}\right)$.

Details are given by

$$
\begin{aligned}
& P_{51}^{I I}\left(T_{R}=l_{r}\right)=P\left(t_{i-1}<X_{1}<t_{i}, t_{i-1}<X_{1}+X_{2}\right. \\
& \left.\quad<t_{i}, X_{1}+X_{2}+X_{3}>l_{r}\right) \\
& \quad=\int_{t_{i-1}}^{t_{i}} \int_{0}^{t_{i}-x} \int_{l_{r}-x-y}^{\infty} f(x, y, z) d z d y d x, \\
& P_{52}^{I I}\left(T_{R}=l_{r}\right)=P\left(t_{i-1}<X_{1}<t_{i}, t_{i-1}<X_{1}+X_{2}\right. \\
& \left.<t_{i}, t_{i}<X_{1}+X_{2}+X_{3}<l_{r}\right) \\
& \quad=\int_{t_{i-1}}^{t_{i}} \int_{0}^{t_{i}-x} \int_{t_{i}-x-y}^{l_{r}-x-y} f(x, y, z) d z d y d x,
\end{aligned}
$$

where $i=1, \ldots, I_{\text {upp }}$.

(4) Instead, if the spare is on hand at the time of identifying the severe defective stage, $t_{i}$, an immediate inspection replacement is performed to renew the system with the following probability:

$$
\begin{aligned}
P_{6}^{I I} & \left(T_{R}=t_{i}\right)=P\left(t_{i-1}<X_{1}<t_{i}, t_{i-1}<X_{1}+X_{2}\right. \\
& \left.<t_{i}, X_{1}+X_{2}+X_{3}>t_{i}\right) \\
& =\int_{t_{i-1}}^{t_{i}} \int_{0}^{t_{i}-x} \int_{t_{i}-x-y}^{\infty} f(x, y, z) d z d y d x,
\end{aligned}
$$

in which

$$
i=I_{\text {low }}, \ldots, \infty, \quad I_{\text {low }}= \begin{cases}L & v\left(l_{r}\right)=0 \\ L+1 & v\left(l_{r}\right)=1 .\end{cases}
$$

Equation (26) indicates the occurrence possibility of case 6.

(5) The severe defective stage is found at an inspection $t_{i, j}$, before which an inspection $t_{i}$ has detected the minor defective stage; however, whether the ordered spare is available or not needs to be measured to make a decision, namely, waiting for the spare until it arrives or replacing the defective system by the available spare immediately. Figure 11(a) means that the former, namely, the arrival time of the spare, is longer than the time of identifying the severe defective stage $l_{r}>t_{i, j}$. The latter is plotted in Figure 11(b). 


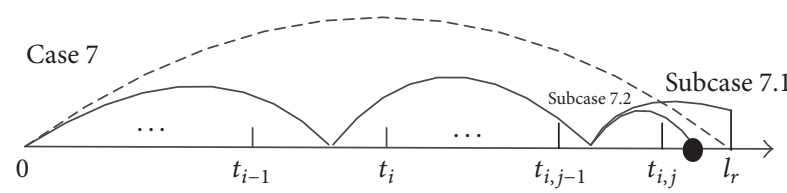

(a)

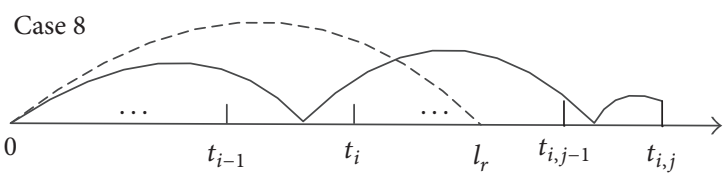

(b)

FIgURE 11: Schematic diagram of case 7 and case 8.

Apparently, there are also two subcases in Figure 11(a) depending on whether the system is still in the severe defective stage when the ordered spare arrives; hence, we obtain the corresponding occurrence probabilities as follows:

$$
\begin{aligned}
& P_{71}^{I I}\left(T_{R}=l_{r}\right)=P\left(t_{i-1}<X_{1}<t_{i}, t_{i, j-1}<X_{1}+X_{2}\right. \\
&\left.\quad<t_{i, j}, X_{1}+X_{2}+X_{3}>l_{r}\right) \\
& \quad=\int_{t_{i-1}}^{t_{i}} \int_{t_{i, j-1}-x}^{t_{i j}-x} \int_{l_{r}-x-y}^{\infty} f(x, y, z) d z d y d x, \\
& P_{72}^{I I}\left(T_{R}=l_{r}\right)=P\left(t_{i-1}<X_{1}<t_{i}, t_{i, j-1}<X_{1}+X_{2}\right. \\
&\left.\quad<t_{i, j}, t_{i, j}<X_{1}+X_{2}+X_{3}<l_{r}\right) \\
& \quad=\int_{t_{i-1}}^{t_{i}} \int_{t_{i, j-1}-x}^{t_{i, j}-x} \int_{t_{i, j}-x-y}^{l_{r}-x-y} f(x, y, z) d z d y d x,
\end{aligned}
$$

where

$$
\begin{aligned}
i & =1, \ldots, I_{\text {upp }}^{\prime} \\
I_{\text {upp }}^{\prime} & = \begin{cases}L-1 & v\left(l_{r}\right)=0 \\
\varphi(L) & v\left(l_{r}\right)=1,\end{cases} \\
\varphi(L) & = \begin{cases}L-1 & l_{r}-\underline{L} \leq \frac{t}{k} \\
L & l_{r}-\underline{L}>\frac{t}{k},\end{cases} \\
j & =1, \ldots, J_{\mathrm{UPP}}, \\
J_{\mathrm{UPP}} & = \begin{cases}J_{\max }-1 & v^{\prime}\left(l_{r}\right)=0 \\
J_{\max } & v^{\prime}\left(l_{r}\right)=1 .\end{cases}
\end{aligned}
$$

The occurrence probability of case 8 can be readily obtained as

$$
\begin{aligned}
P_{8}^{I I} & \left(T_{R}=t_{i, j}\right)=P\left(t_{i-1}<X_{1}<t_{i}, t_{i, j-1}<X_{1}+X_{2}\right. \\
& \left.<t_{i, j}, X_{1}+X_{2}+X_{3}>t_{i, j}\right) \\
& =\int_{t_{i-1}}^{t_{i}} \int_{t_{i, j-1}-x}^{t_{i, j}-x} \int_{t_{i, j}-x-y}^{\infty} f(x, y, z) d z d y d x,
\end{aligned}
$$

where

$$
\begin{aligned}
i & =1, \ldots, \infty, \\
j & =J_{\text {Low }}^{\prime}, \ldots, \infty, \\
J_{\text {Low }}^{\prime} & = \begin{cases}1 & l_{r} \leq t_{i} \\
\rho^{\prime}\left(J_{\max }\right) & l_{r}>t_{i},\end{cases} \\
\rho^{\prime}\left(J_{\max }\right) & = \begin{cases}J_{\max } & v^{\prime}\left(l_{r}\right)=0 \\
J_{\max }+1 & v^{\prime}\left(l_{r}\right)=1 .\end{cases}
\end{aligned}
$$

Similar to the derivation of (14) and (15) in model $I$ and based on the probabilities of all possible cases, shown in (17), (19), (21), (23), (25), (26), (28), and (31), we obtain the expected renewal cycle cost and length of policy $I I$, $E_{C}^{I I}(t, k), E_{L}^{I I}(t, k)$, as follows:

$$
\begin{aligned}
& E_{C}^{I I}(t, k)=\left\{\sum_{i=1}^{L}\left[(i-1) c_{i}+c_{f}+c_{p}^{f} \cdot\left(l_{r}-T_{f}\right)+c_{R}^{r}\right]\right. \\
& \cdot P_{11}^{I I}\left(t_{i-1}<T_{f}<t_{i}\right)+\left[L c_{i}+c_{f}+c_{p}^{f} \cdot\left(l_{r}-T_{f}\right)+c_{R}^{r}\right] \\
& \cdot P_{12}^{I I}\left(\underline{L}<T_{f}<l_{r}\right)+\left[L c_{i}+c_{f}+c_{h} \cdot\left(T_{f}-l_{r}\right)+c_{R}^{r}\right] \\
& \cdot P_{21}^{I I}\left(l_{r}<T_{f}<\bar{L}\right)+\sum_{i=I}^{\infty}\left[(i-1) c_{i}+c_{f}+c_{h} \cdot\left(T_{f}-l_{r}\right)\right. \\
& \left.+c_{R}^{r}\right] \cdot P_{22}^{I I}\left(t_{i-1}<T_{f}<t_{i}\right) \\
& +\sum_{i=1}^{I_{\text {upp }}} \sum_{j=1}^{J_{\max }}\left[(i+j-1) c_{i}+c_{f}+c_{p}^{f} \cdot\left(l_{r}-T_{f}\right)+c_{R}^{r}\right] \\
& \cdot P_{31}^{I I}\left(t_{i, j-1}<T_{f}<t_{i, j}\right)+\sum_{i=1}^{I_{\text {upp }}}\left[\left(i+J_{\max }\right) c_{i}+c_{f}+c_{p}^{f}\right. \\
& \left.\cdot\left(l_{r}-T_{f}\right)+c_{R}^{r}\right] \cdot P_{32}^{I I}\left(\underline{L^{\prime}}<T_{f}<l_{r}\right)+\sum_{i=1}^{I_{\text {upp }}}\left[\left(i+J_{\max }\right) c_{i}\right. \\
& \left.+c_{f}+c_{h} \cdot\left(T_{f}-l_{r}\right)+c_{R}^{r}\right] \cdot P_{41}^{I I}\left(l_{r}<T_{f}<\overline{L^{\prime}}\right) \\
& +\sum_{i=1}^{\infty} \sum_{j=J_{\text {Low }}}^{\infty}\left[(i+j-1) c_{i}+c_{f}+c_{h} \cdot\left(T_{f}-l_{r}\right)+c_{R}^{r}\right] \\
& \cdot P_{42}^{I I}\left(t_{i, j-1}<T_{f}<t_{i, j}\right)+\sum_{i=1}^{I_{\text {upp }}}\left[i c_{i}+c_{p}^{w} \cdot\left(l_{r}-t_{i}\right)+c_{R}^{r}\right] \\
& \cdot P_{51}^{I I}\left(T_{R}=l_{r}\right)+\sum_{i=1}^{I_{\text {upp }}}\left[i c_{i}+c_{p}^{w} \cdot\left(T_{f}-t_{i}\right)+c_{p}^{f} \cdot\left(l_{r}-T_{f}\right)\right. \\
& \left.+c_{R}^{r}\right] \cdot P_{52}^{I I}\left(T_{R}=l_{r}\right)+\sum_{i=I_{\text {low }}}^{\infty}\left[i c_{i}+c_{h} \cdot\left(t_{i}-l_{r}\right)+c_{R}^{r}\right]
\end{aligned}
$$




$$
\begin{aligned}
& \cdot P_{6}^{I I}\left(T_{R}=t_{i}\right)+\sum_{i=1}^{I_{\text {upp }}^{\prime}} \sum_{j=1}^{U_{\text {upp }}}\left[(i+j) c_{i}+c_{p}^{w} \cdot\left(l_{r}-t_{i, j}\right)+c_{R}^{r}\right] \\
& \cdot P_{71}^{I I}\left(T_{R}=l_{r}\right) \\
& +\sum_{i=1}^{I_{\text {upp }}^{\prime}} \sum_{j=1}^{J_{\mathrm{Upp}}}\left[(i+j) c_{i}+c_{p}^{w} \cdot\left(T_{f}-t_{i, j}\right)+c_{p}^{f} \cdot\left(l_{r}-T_{f}\right)+c_{R}^{r}\right] \\
& \cdot P_{72}^{I I}\left(T_{R}=l_{r}\right)+\sum_{i=1}^{\infty} \sum_{j=I_{\text {Low }}^{\prime}}^{\infty}\left[(i+j) c_{i}+c_{h} \cdot\left(t_{i, j}-l_{r}\right)+c_{R}^{r}\right] \\
& \left.\cdot P_{8}^{I I}\left(T_{R}=t_{i, j}\right)\right\} \text {, }
\end{aligned}
$$

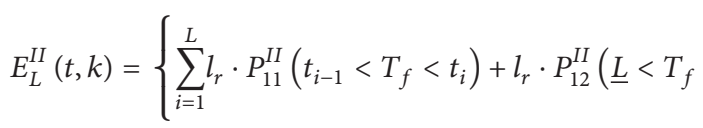

$$
\begin{aligned}
& \left.<l_{r}\right)+T_{f} \cdot P_{21}^{I I}\left(l_{r}<T_{f}<\bar{L}\right)+\sum_{i=I}^{\infty} T_{f} \cdot P_{22}^{I I}\left(t_{i-1}<T_{f}\right. \\
& \left.<t_{i}\right)+\sum_{i=1}^{I_{\text {upp }}} \sum_{j=1}^{J_{\max }} l_{r} \cdot P_{31}^{I I}\left(t_{i, j-1}<T_{f}<t_{i, j}\right)+\sum_{i=1}^{I_{\text {upp }}} l_{r} \cdot P_{32}^{I I}\left(\underline{L^{\prime}}\right. \\
& \left.<T_{f}<l_{r}\right)+\sum_{i=1}^{I_{\text {upp }}} T_{f} \cdot P_{41}^{I I}\left(l_{r}<T_{f}<\overline{L^{\prime}}\right)+\sum_{i=1}^{\infty} \sum_{j=I_{\text {Low }}}^{\infty} T_{f} \\
& \cdot P_{42}^{I I}\left(t_{i, j-1}<T_{f}<t_{i, j}\right)+\sum_{i=1}^{I_{\text {upp }}} l_{r} \cdot P_{51}^{I I}\left(T_{R}=l_{r}\right)+\sum_{i=1}^{I_{\text {upp }}} l_{r} \\
& \cdot P_{52}^{I I}\left(T_{R}=l_{r}\right)+\sum_{i=I_{\text {low }}}^{\infty} t_{i} \cdot P_{6}^{I I}\left(T_{R}=t_{i}\right)+\sum_{i=1}^{I_{\text {upp }}^{\prime} \sum_{j=1}^{J \text { Upp }}} l_{r} \\
& \cdot P_{71}^{I I}\left(T_{R}=l_{r}\right)+\sum_{i=1}^{I_{\text {upp }}^{\prime}} \sum_{j=1}^{J_{\text {Upp }}} l_{r} \cdot P_{72}^{I I}\left(T_{R}=l_{r}\right)+\sum_{i=1}^{\infty} \sum_{j=J_{\text {Low }}^{\prime}}^{\infty} t_{i, j} \\
& \left.\cdot P_{8}^{I I}\left(T_{R}=t_{i, j}\right)\right\} \text {. }
\end{aligned}
$$

Then, the optimization model can be constructed as $C^{I I}(t, k)=E_{C}^{I I}(t, k) / E_{L}^{I I}(t, k)$ to find the optimal decision variables, $t^{*}, k^{*}$.

\section{Numerical Example}

5.1. Initial Modeling Parameters. In order to solve models $I$ and $I I$, the first step is to set modeling parameters, (i.e., $\left.c_{i}, c_{f}, c_{p}^{w}, c_{p}^{f}, c_{h}, c_{R}^{r}, c_{R}^{e}, l_{r}\right)$ that are given in Table 5 by experience from the industry. The chosen calendar time unit is here one day and the cost is measured in 10,000 yuan. Since the lead time of the emergency order is assumed to be random, the distribution that it follows needs to be preset. The normal distribution is chosen and used to describe the distribution of the emergency ordering lead time, so we adopt it in the numerical example given below with the form $g\left(l_{e}\right)=(1 / \sigma \sqrt{2 \pi}) e^{-\left(l_{e}-\mu\right)^{2} / 2 \sigma^{2}}$, in which $\mu$ and $\sigma$ are the mean and standard deviation of the random lead time $l_{e}$.
TABLE 5: Initial parameters.

\begin{tabular}{cccccccc}
\hline$c_{i}$ & $c_{f}$ & $c_{p}^{w}$ & $c_{p}^{f}$ & $c_{h}$ & $c_{R}^{r}$ & $c_{R}^{e}$ & $l_{r}$ \\
\hline 5 & 200 & 1 & 2 & 0.5 & 30 & 50 & 60 \\
\hline
\end{tabular}

TABLE 6: Distribution parameters.

\begin{tabular}{lccccccc}
\hline$\alpha_{1}$ & $\beta_{1}$ & $\alpha_{2}$ & $\beta_{2}$ & $\alpha_{3}$ & $\beta_{3}$ & $\mu$ & $\sigma$ \\
\hline 0.018 & 1.81 & 0.015 & 1.41 & 0.037 & 1.70 & 4 & 0.5 \\
\hline
\end{tabular}

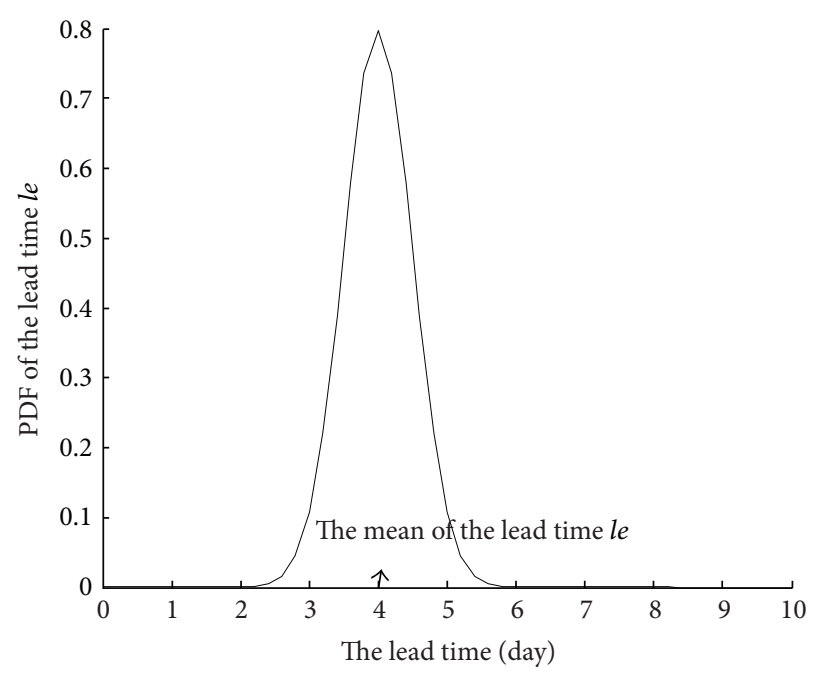

Figure 12: The PDF of the lead time $l_{e}$.

The random durations of three stages in the deterioration process are assumed to follow the Weibull distribution, which is one of the most common distributions in reliability studies [22]. The probability density function (PDF) of the Weibull distribution is shown in (34), in which $\alpha_{n}$ and $\beta_{n}$ denote the scale parameter and the shape parameter, respectively. Furthermore, the distribution parameters are shown in Table 6 and on the basis of them the expected lengths of these three stages are $E\left(X_{1}\right)=52.2972$ days, $E\left(X_{2}\right)=60.6945$ days, and $E\left(X_{3}\right)=24.1147$ days, respectively. The PDF of the emergency ordering lead time $l_{e}$ is plotted in Figure 12 for illustration based on the preset parameters in Table 6 .

$$
\begin{aligned}
& X_{n} \sim \text { Weibull }\left(\alpha_{n}, \beta_{n}\right) ; \\
& f_{X_{n}}(x)=\alpha_{n} \cdot \beta_{n} \cdot\left(\alpha_{n} \cdot x\right)^{\beta_{n}-1} \cdot e^{-\left(\alpha_{n} \cdot x\right)^{\beta_{n}}} \\
& \alpha_{n}>0, \beta_{n}>0 .
\end{aligned}
$$

5.2. Simulation Algorithm Based on Discrete Events. The calculation of convolution integrals in the presented models $I$ and $I I$ is time-consuming but can be solved. For this, we design the simulation algorithm based on discrete events in the light of problem description to reduce the computation complexity. Figure 13 gives the flow chart of the simulation algorithm for model $I$, and refer to Appendix for that of model II. Naturally, the first step is to set the initial parameters used in the optimization model, some of which 


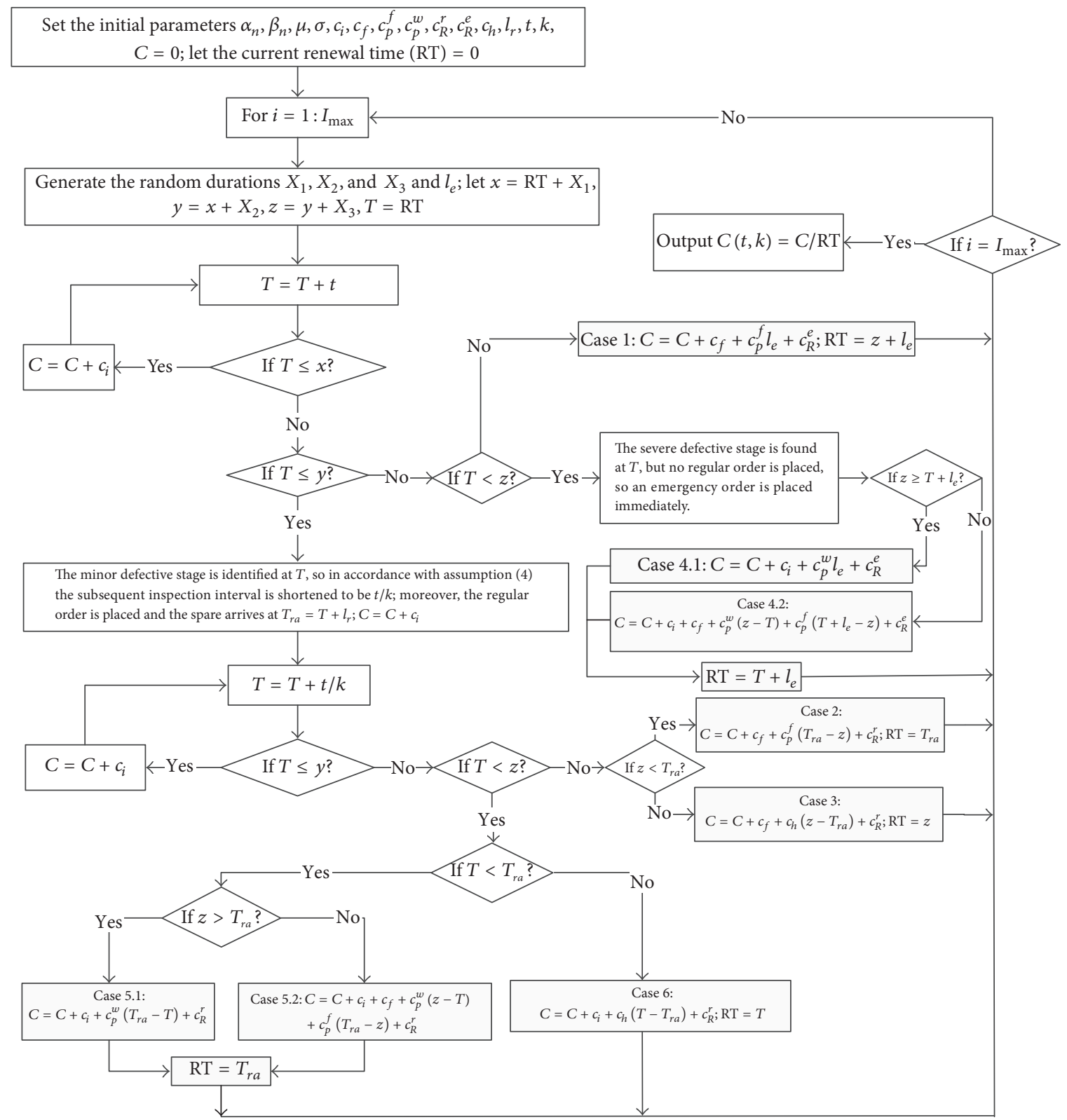

Figure 13: The flow chart of the simulation algorithm for model $I$.

have been determined in Section 5.1. Let $C$ denote the total cost in the simulation process that includes inspection cost, failure loss, penalty cost caused by shortage, holding cost, and replacement costs due to a regular order and an emergency order. Meanwhile, the simulation starts from the initial time $\mathrm{RT}=0$, in which RT is defined as the renewal time. Repeat the simulation to calculate the long-run expected cost per unit time until the termination condition, that is, a maximum number of iteration $I_{\max }$, is reached. According to the given distribution parameters, generate the random durations of three stages $X_{1}, X_{2}, X_{3}$ and the lead time of an emergency order $l_{e}$, and compute the end points of three stages $x, y, z$. As the simulation goes, judge whether the current time $T$ is not larger than the end point of the first stage, that is,
$T \leq x$. If this condition is met, then we have $C=C+c_{i}$ and let $T=T+t$ continue the simulation; otherwise, we need to further make a judgment for another condition, $T \leq y$. Obviously, if $T \leq y$ is met, indicating that the minor defective stage is identified, then the original inspection interval $t$ is shortened to be $t / k$ to have more chances to check the system according to assumption (4). Additionally, by the discussion in Introduction and Section 2.2, it also provides the warning to place the regular order at the time of identifying the minor defective stage, and the spare arrives at $T_{r a}=T+l_{r}$ after the delivery time $l_{r}$. Followed by it, compute the total cost by summing up the cost resulting from inspections as long as the condition $T \leq y$ is satisfied. Next, determine whether the system fails before the next inspection or not, namely, 


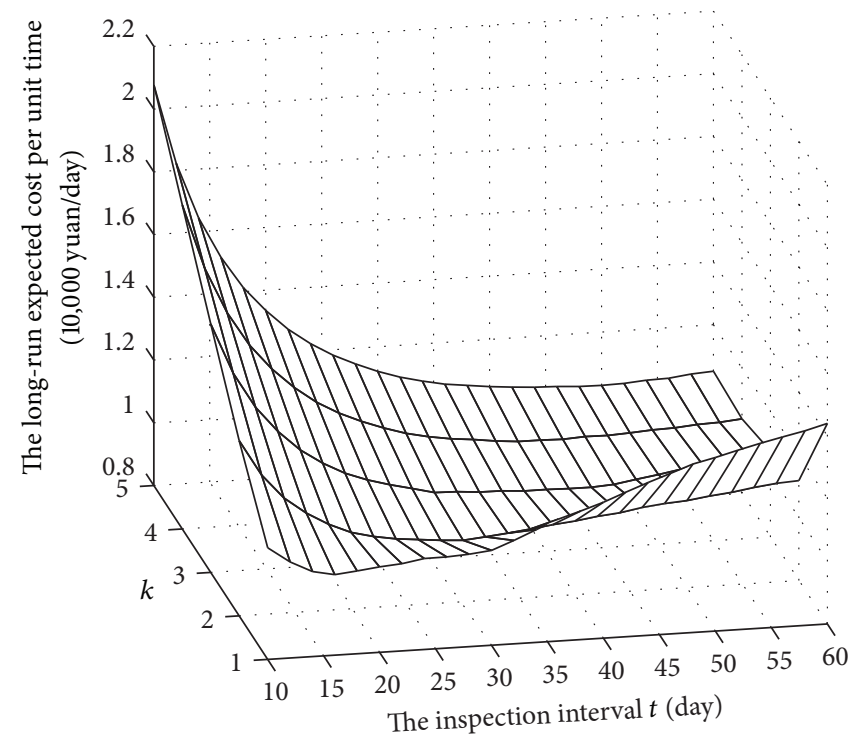

(a) Results from the analytical model

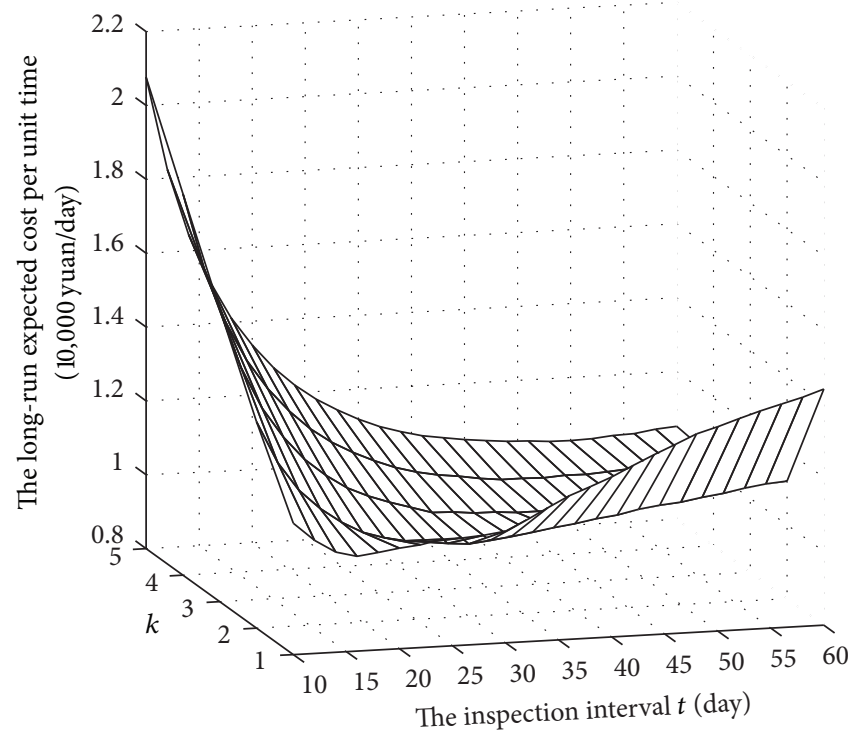

(b) Results from the simulation algorithm

FIGURE 14: Long-run expected cost per unit time of policy I obtained from model $I$ (16) and the simulation algorithm (Figure 13).

$T<z$. When the inequality $T<z$ is rejected, a failure arises before $T$, which leads to case 2 and case 3 relying on the availability of the regular ordered spare at the failure time $z$. However, when the inequality $T<z$ holds, implying that the severe defective stage is detected at $T$, it requires an inspection replacement in terms of assumption (5). But taking into consideration the availability of the spare, case 5 and case 6 are caused and there are two subcases 5.1 and 5.2 for case 5 , as discussed above. It is noted that the minor defective stage may be missed by inspection; namely, the condition $T \leq y$ is not met. Therefore, whether the severe defective stage can be identified by inspection needs to be judged, that is, $T<z$. If the simulation time $T$ is smaller than the end point of the severe defective stage $z$, an inspection replacement is needed, resulting in a delayed inspection replacement at the arrival time of the emergency ordered spare $T+l_{e}$, as stated in case 4 . Besides, $T \geq z$ shows that the system has been in the failed state before the next inspection, which requires a failure replacement. But because no regular order is placed until $z$, an emergency order is placed at $z$ and the replacement is postponed and performed at $z+l_{e}$, that is, case 1. Eventually, the objective function $C(t, k)$ is calculated under the different combinations of $t$ and $k$.

\subsection{Results and Analysis of Model I from Different Methods.} Using the above parameters, we calculate the long-run expected cost per unit time of model $I$ under the combinations of different inspection interval $t$ and the value of $k$ based on the analytical model and the simulation algorithm, respectively. The corresponding results obtained from them are given and shown in Figures 14(a) and 14(b), from which we can observe that there is a slight difference between them. More specifically, the optimal solutions from the analytical model (see (16)) are $t^{*}=42$ days and $k^{*}=3$ with the minimal expected cost per unit time, 0.9949; meanwhile, the decision variables optimized by the simulation algorithm designed in Figure 13 are also $t^{*}=42$ days and $k^{*}=3$ but with a different minimal expected cost per unit time, 0.9937. Obviously, the proposed simulation algorithm can be applied to optimize the joint policy of inspection-based $\mathrm{PM}$ and spare ordering. Note that when the value of $k$ is determined, the long-run expected cost per unit time reduces first and then increases with the increase of the inspection interval $t$. It can be explained that more frequent inspection actions with smaller inspection $t$ lead to higher inspection costs, but the inspection scheme with longer interval $t$ may miss the identification of defects, resulting in a system failure and bringing about higher cost loss. It is also in line with our previous studies and the practice. $k=1$ means that there is an inspection plan with a fixed interval which has been assumed in most studies, and from Figure 14 it can be easily concluded that when the system has been detected to be in the minor defective stage, shortening the inspection interval is a better option compared with keeping it unchanged. Also, Figure 15 illustrates the long-run expected cost per unit time against the inspection interval under $k=2,3,4$ according to the results in Figure 14(b). It is clearly seen from Figure 15 that the objective function is minimized to be 0.9937 when $k^{*}=3$; that is, if the minor defective is revealed, the original inspection interval $t^{*}=42$ days should be shortened to be $t^{*} / k^{*}=42 / 3=12$ days. Otherwise, it will cause the increase of the expected cost per unit time due to either a failure unrecognized in advance or more frequent inspection activities.

5.4. Comparative Studies of Model I and Model II. Depending on whether the regular order is placed at the beginning of the system operation, the joint policies I and II are developed 


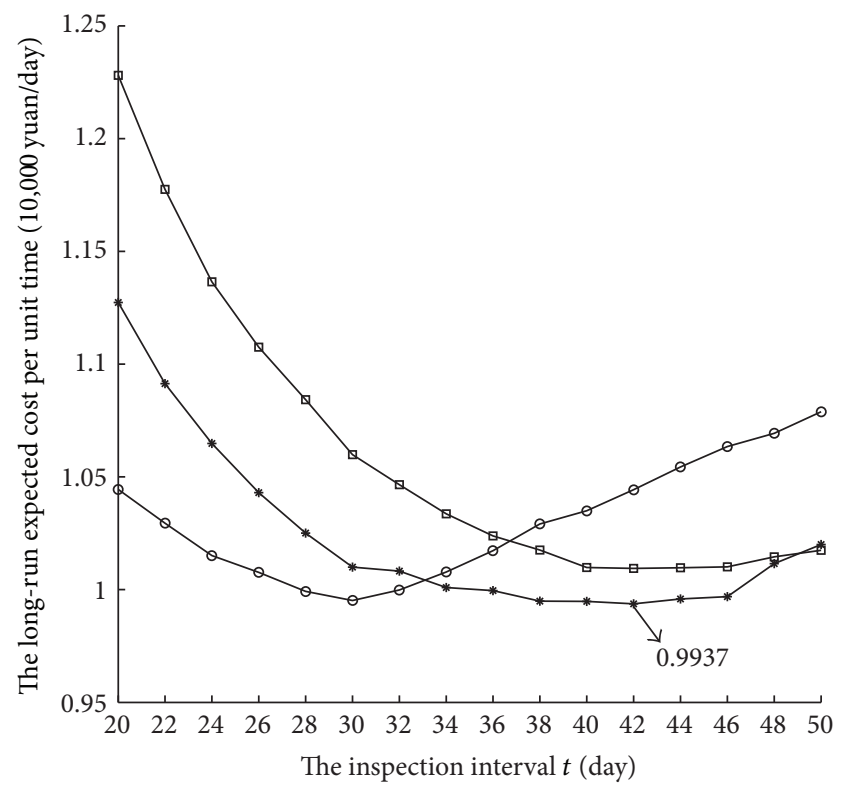

$$
\begin{aligned}
& \rightarrow k=2 \\
& \rightarrow-k=3 \\
& \rightarrow-k=4
\end{aligned}
$$

FIGURE 15: Long-run expected cost per unit time against the inspection interval $t$.

and the corresponding models are established. Then, we give the comparative studies for them here. Using the simulation algorithm of model $I I$ in Appendix, the long-run expected cost per unit time is minimized to find the optimal $t^{*}, k^{*}$. The obtained results are given in Figure 16, based on which we obtain $t^{*}=34$ days and $k^{*}=3$ and the minimal longrun expected cost per unit time is 1.0688. It is not hard to see that the long-run expected cost per unit time of model II to be minimized is larger than that of model $I$ since 1.0688 $>0.9937,7.56$ percent more than model $I$. Thus, the more economical solution is to place the regular order at the time of identifying the minor defective stage rather than at the beginning of the system operation. It is most likely because placing order at time 0 may incur a higher holding cost than ordering at the identification time of the minor defective stage by perfect inspections. More interestingly, the optimal inspection interval under model $I I$ is smaller than that of model $I$, that is, $34<42$, which is as we expected. Obviously, the cost resulting from inspections with a smaller interval may lead to the increase of the long-run expected cost per unit time. However, we have to note that the result of this numerical example is suitable under the given parameters; recalculation is done if parameters change and it may cause different optimal solutions.

Note that model $I$ and model $I I$ are developed based on an assumption that the inspection interval is shortened once the minor defective stage is identified, as mentioned in assumption (4) of Section 2.1. Such an irregular inspection policy is optimized and the results of Figures 15 and 16 illustrate the performance of the inspection policy with irregular interval; that is, $k^{*}=3$, indicating that, after the identification of the

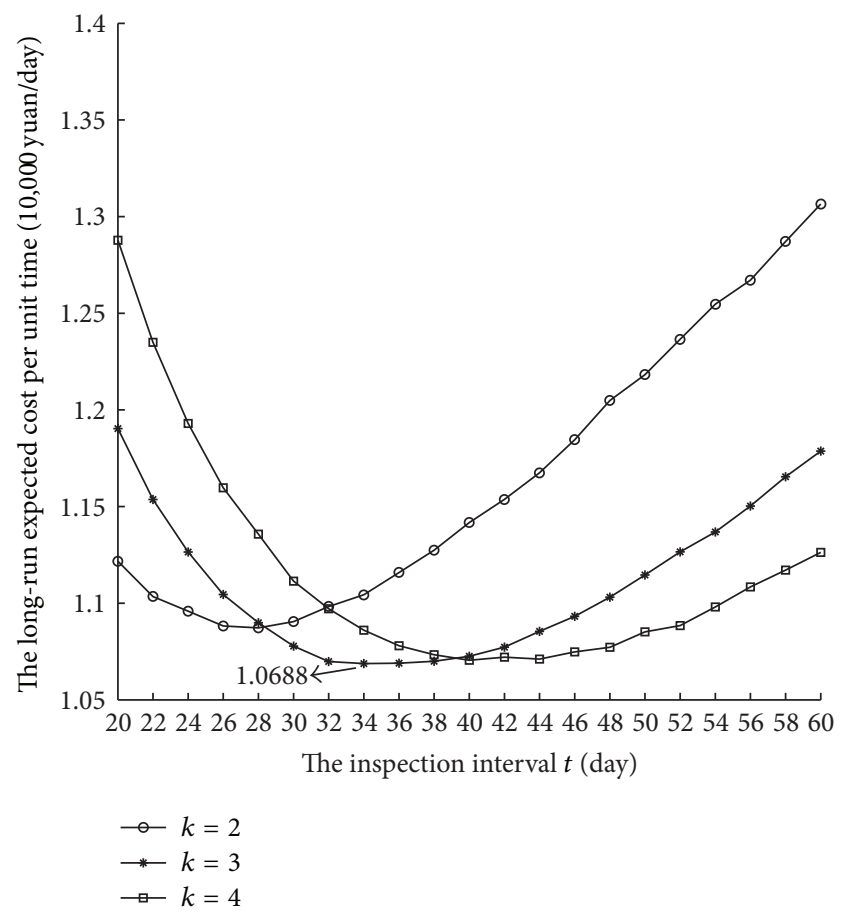

FIGURE 16: Long-run expected cost per unit time of model II.

minor defective stage, the interval of subsequent inspections should be one-third of the initial inspection interval $t$. To further check whether the irregular inspection policy is reasonable, different simulations are conducted by relaxing the assumption of irregular interval imposed on model $I$ and model II. Figure 17 gives the results of the long-run expected cost per unit time in the case of a joint policy of regular inspection-based PM and spare ordering; that is to say, inspections are performed with a constant time interval. Figure 17(a) corresponds to the situation that two modes of spare ordering are specialized, but the regular ordering is only considered in Figure 17(b). It is realized that the irregular inspection intervals have a better capability of minimizing the long-run expected cost per unit time than the regular inspection intervals from $0.9937<1.0543$ and $1.0688<1.1669$. As expected, it can be observed from Figure 17 that the optimal intervals under regular inspection policy are shorter than those under irregular inspection policy, that is, $16<42$ and $15<34$.

5.5. Sensitivity Analysis. This subsection is contributed to explore the influence of the change of different parameters on the decision-making results. Table 7 gives the sensitivity analyses results, in which the percentage of each parameter's increase or decrease is $+10 \%,-10 \%$, respectively, while keeping other parameters unvaried. The last column gives the percentage of the change of the minimal objective function after each parameter is adjusted compared to the result under the original parameters shown in Figure 14, 0.9937. It is reasonable that the minimal long-run expected cost per unit time, $C^{I}\left(t^{*}, k^{*}\right)$, increases with the increase of any cost parameter and decreases as the cost parameter reduces. 


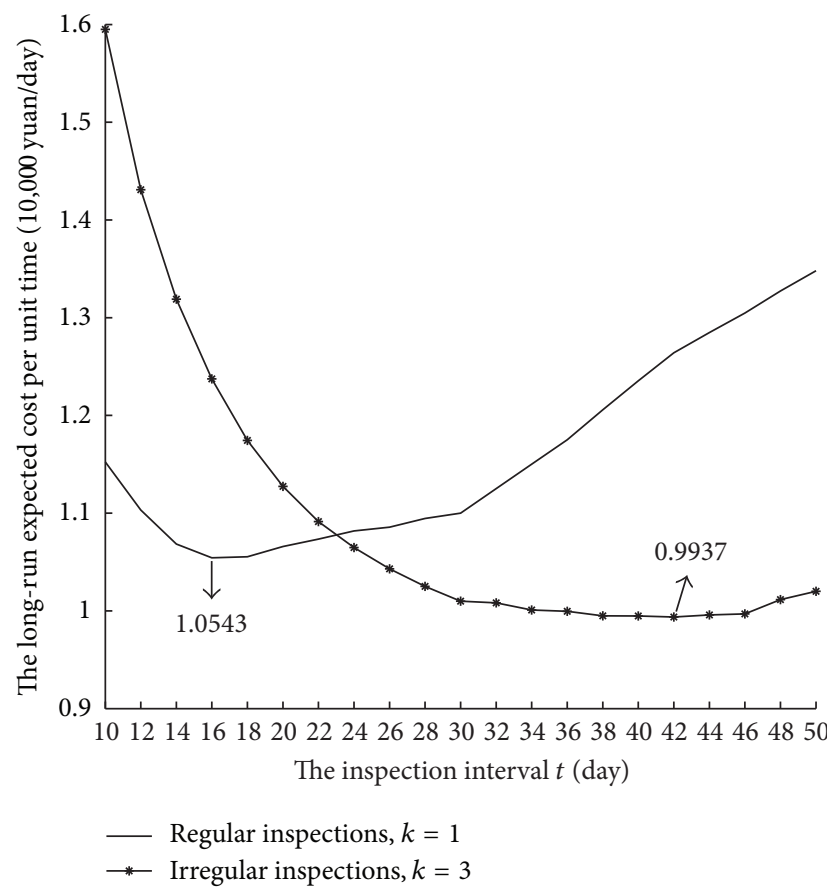

(a) Situation in consideration of two modes of spare ordering

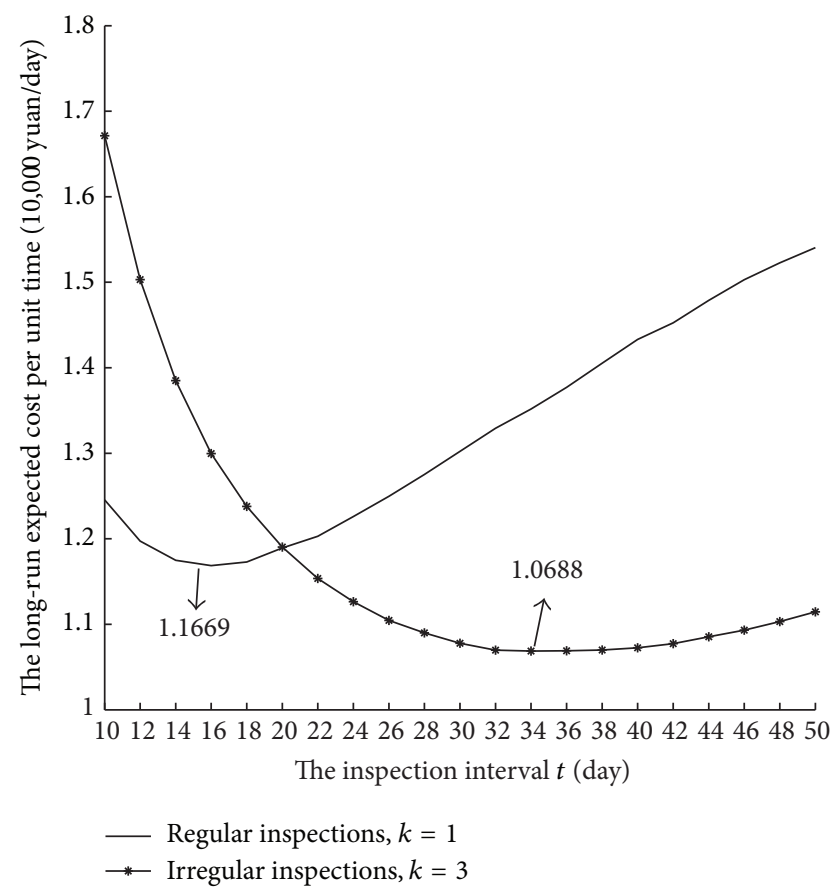

(b) Situation with the regular order only

FIGURE 17: Results from regular and irregular inspections.

It can be concluded from the results in Table 7 that the greatest influence on $C^{I}\left(t^{*}, k^{*}\right)$ is the average cost due to failure, $c_{f}$; therefore, once there is an obvious change for $c_{f}$, managers should be concerned with decisions for the inspection interval $t$ and $k$. We can observe that the optimal inspection interval is prolonged to 44 days with the decrease of $c_{f}$; alternatively, it is shortened to 30 days when the failure cost moves to 220. Followed by it, it can be noted that the parameters due to inspection and holding the spare have a relatively large effect on the decision compared to other parameters.

\section{Conclusions}

The joint policy of inspection-based PM and spare ordering is proposed for a single-unit system in this study, in which the three-stage deterioration process is introduced to depict the system lifetime. Thus, it is assumed that when the minor defective stage is found by an inspection, it provides a chance for managers to place a regular order and in order to check the system more frequently, shortening the original inspection interval is also considered. However, once the system is detected to be in the severe defective stage, replacing the system preventively is required; also, a corrective replacement should be done to bring the failed system to an as-goodas-new state. A spare is needed for either replacement, so in order to model such a joint policy different scenarios are taken into account relying on the system state and the state of the regular ordered spare. Moreover, an emergency order is also introduced once no regular order is placed. Then, we establish the optimization model of the proposed joint policy by minimizing the long-run expected cost per unit time to find the optimal inspection interval and the times that the original inspection interval is shortened. In order to illustrate the proposed joint policy, another joint policy in which the regular order is placed at the beginning of the system operation is also developed and modeled. The results from the numerical example show that placing the regular order at the time of identifying the minor defective stage is more economical compared to the traditional policy and the results of the comparison of the proposed policy to the joint policy with regular inspections illustrate that our joint policy with irregular inspections performs well. Also, the sensitivity analysis concluded that the average cost parameter due to failure is the most sensitive one under the same percentage change of a cost parameter.

There are some further research topics to which attention can be paid in the future. The first is to relax the assumption that a maximum of one spare unit is ordered and stored; secondly, this work can be extended to the situation of multiunit complex system; the third direction is to consider imperfect repair for severe defective systems since it is closer to the reality.

\section{Appendix}

Figures 18-20 show the flow chart of simulation algorithm of model II, in which the process is designed based on policy II mentioned and discussed in Section 4. For similarity, the description is omitted. 
TABLE 7: Sensitivity analysis results.

\begin{tabular}{|c|c|c|c|c|c|c|}
\hline \multicolumn{3}{|c|}{ Parameter } & \multirow{2}{*}{$\begin{array}{l}t^{*} \\
30\end{array}$} & \multirow{2}{*}{$\frac{k^{*}}{2}$} & \multicolumn{2}{|c|}{$C^{I}\left(t^{*}, k^{*}\right)$} \\
\hline \multirow{2}{*}{$c_{i}$} & 4.5 & $-10 \%$ & & & 0.9724 & $-2.15 \%$ \\
\hline & 5.5 & $+10 \%$ & 30 & 2 & 1.0155 & $2.19 \%$ \\
\hline \multirow{2}{*}{$c_{f}$} & 180 & $-10 \%$ & 44 & 3 & 0.9597 & $-3.42 \%$ \\
\hline & 220 & $+10 \%$ & 30 & 2 & 1.0281 & $3.46 \%$ \\
\hline \multirow{2}{*}{$c_{p}^{w}$} & 0.9 & $-10 \%$ & 30 & 2 & 0.9904 & $-0.33 \%$ \\
\hline & 1.1 & $+10 \%$ & 40 & 3 & 0.9954 & $0.17 \%$ \\
\hline \multirow{2}{*}{$c_{p}^{f}$} & 1.8 & $-10 \%$ & 42 & 3 & 0.9963 & $-0.26 \%$ \\
\hline & 2.2 & $+10 \%$ & 30 & 3 & 0.9986 & $0.49 \%$ \\
\hline \multirow{2}{*}{$c_{h}$} & 0.45 & $-10 \%$ & 30 & 2 & 0.9827 & $-1.10 \%$ \\
\hline & 0.55 & $+10 \%$ & 30 & 2 & 1.0076 & $1.40 \%$ \\
\hline
\end{tabular}

Set the initial parameters $\alpha_{n}, \beta_{n}, c_{i}, c_{f}, c_{p}^{f}, c_{p}^{w}, c_{R}^{r}, c_{h}, l_{r}, t, k, C=0$; let the current renewal time $(\mathrm{RT})=0$

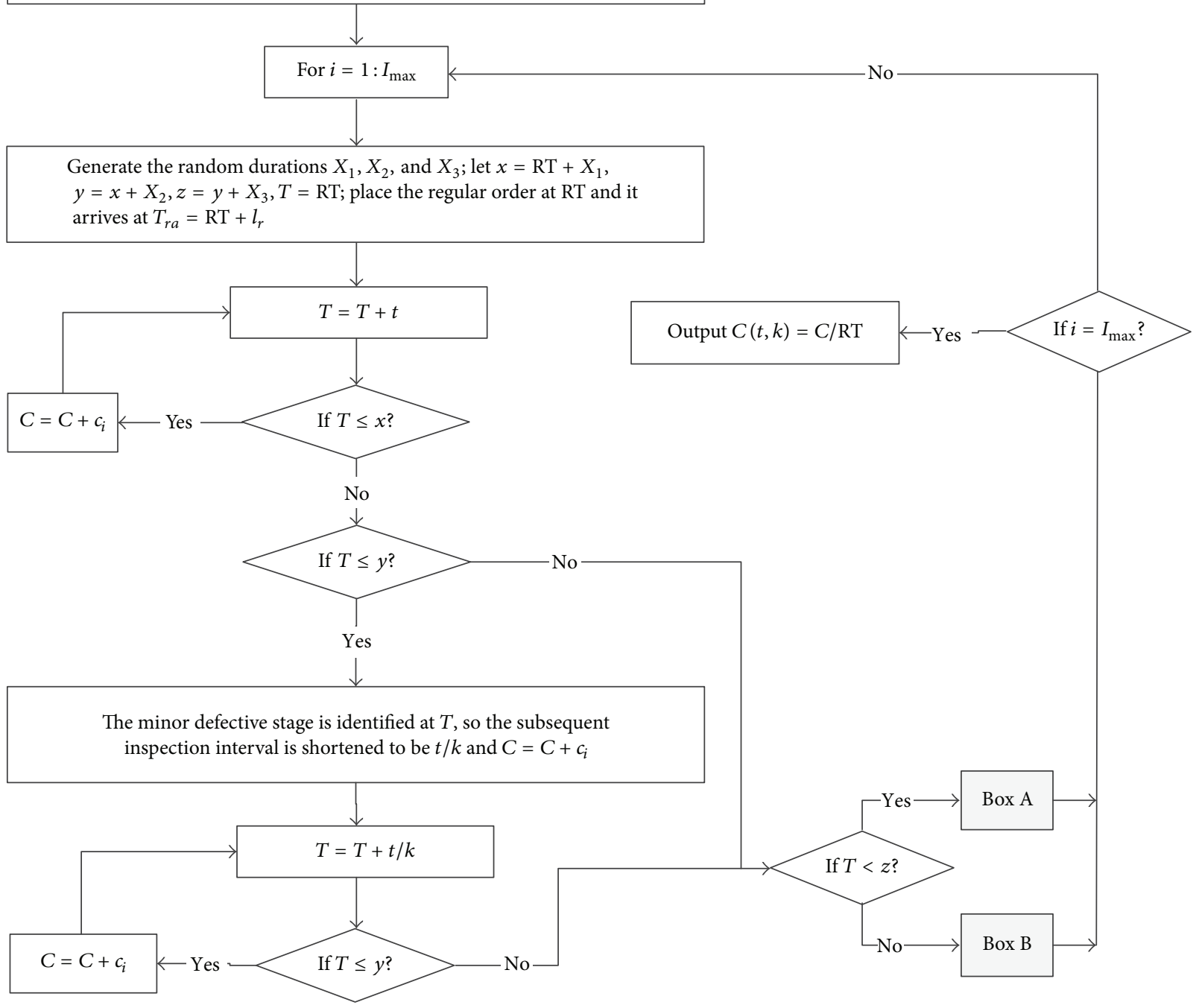

FIGURE 18: The flow chart of simulation algorithm for model II. 


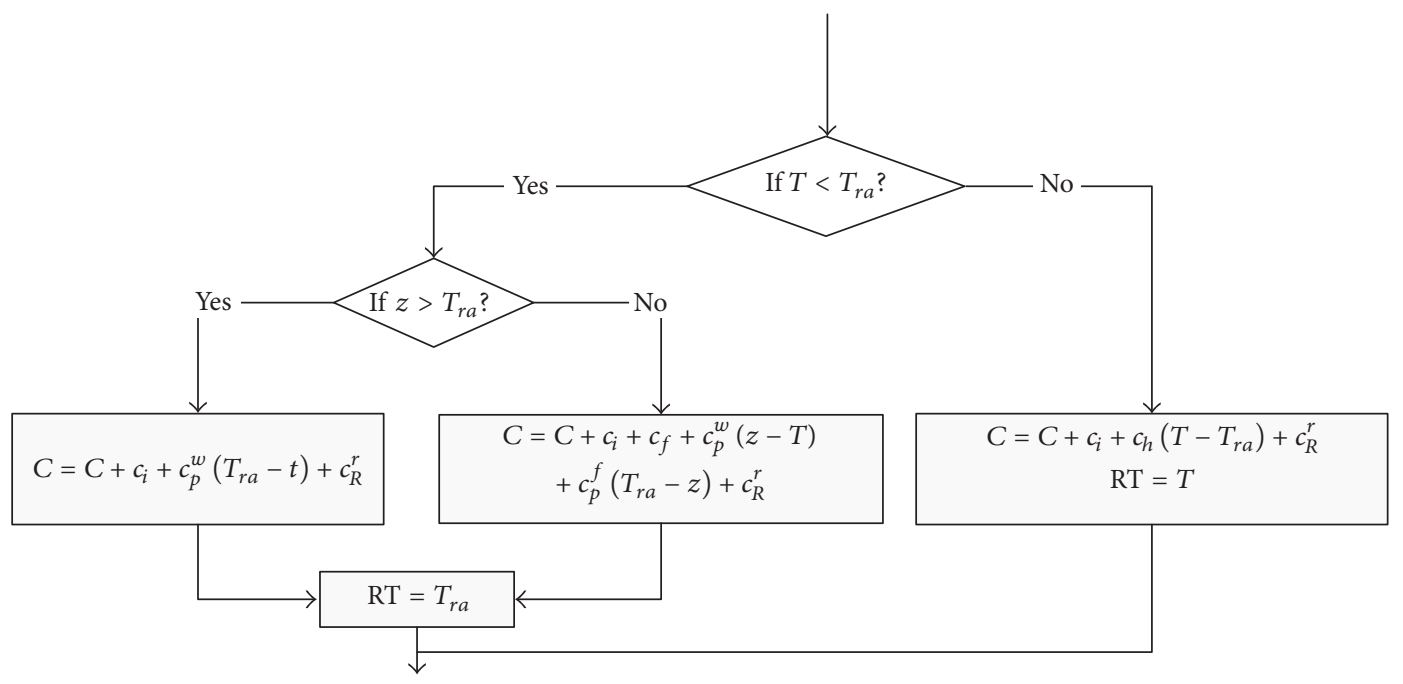

Figure 19: Box A.

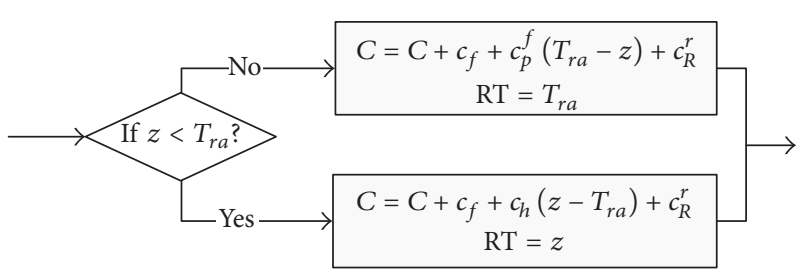

Figure 20: Box B.

\section{Conflicts of Interest}

The authors declare that they have no conflicts of interest.

\section{Acknowledgments}

This research report is partially supported by the NSFC (71701038, 71701037, and 71601019), China Ministry of Education Humanities and Social Sciences Research Youth Fund Project (16YJC630174), the Fundamental Research Funds for the Central Universities of China (N152303004), Hebei Province High School Science and Technology Research Project (QN2017104), Hebei Province Soft Science Research Planning Project (16457402D), and the Fundamental Research Funds for Northeastern University at Qinhuangdao (XNB201616).

\section{References}

[1] A. K. S. Jardine, D. Lin, and D. Banjevic, "A review on machinery diagnostics and prognostics implementing condition-based maintenance," Mechanical Systems and Signal Processing, vol. 20, no. 7, pp. 1483-1510, 2006.

[2] T. D. Dimitrakos and E. G. Kyriakidis, "An improved algorithm for the computation of the optimal repair/replacement policy under general repairs," European Journal of Operational Research, vol. 182, no. 2, pp. 775-782, 2007.
[3] H. R. Golmakani and M. Pouresmaeeli, "Optimal replacement policy for condition-based maintenance with non-decreasing failure cost and costly inspection," Journal of Quality in Maintenance Engineering, vol. 20, no. 1, pp. 51-64, 2014.

[4] N. Chen, Z.-S. Ye, Y. Xiang, and L. Zhang, "Condition-based maintenance using the inverse Gaussian degradation model," European Journal of Operational Research, vol. 243, no. 1, pp. 190-199, 2015.

[5] T. Nakagawa, "Periodic inspection policy with preventive maintenance," Naval Research Logistics Quarterly, vol. 31, no. 1, pp. 33-40, 1984.

[6] F. G. Badía, M. D. Berrade, and C. A. Campos, "Optimal inspection and preventive maintenance of units with revealed and unrevealed failures," Reliability Engineering \& System Safety, vol. 78, no. 2, pp. 157-163, 2002.

[7] Y.-C. Chen, "An optimal production and inspection strategy with preventive maintenance error and rework," Journal of Manufacturing Systems, vol. 32, no. 1, pp. 99-106, 2013.

[8] K. S. Moghaddam and J. S. Usher, "A new multi-objective optimization model for preventive maintenance and replacement scheduling of multi-component systems," Engineering Optimization, vol. 43, no. 7, pp. 701-719, 2011.

[9] P. Do, H. C. Vu, A. Barros, and C. Bérenguer, "Maintenance grouping for multi-component systems with availability constraints and limited maintenance teams," Reliability Engineering \& System Safety, vol. 142, pp. 56-67, 2015.

[10] A. Kumar, S. K. Chhillar, and S. C. Malik, "Analysis of a singleunit system with degradation and maintenance," Journal of Statistics \& Management Systems, vol. 19, no. 2, pp. 151-161, 2016.

[11] S. Osaki and S. Yamada, "Age replacement with leadtime," IEEE Transactions on Reliability, vol. R-25, no. 5, pp. 344-345, 1976.

[12] S.-H. Sheu and W. S. Griffith, "Optimal age-replacement policy with age-dependent minimal-repair and random-leadtime," IEEE Transactions on Reliability, vol. 50, no. 3, pp. 302-309, 2001.

[13] J.-P. Jhang, "A generalized age replacement policy with random delivery time and inspection," International Journal of Systems Science, vol. 32, no. 3, pp. 321-329, 2001. 
[14] S. H. Sheu and Y. H. Chien, "Optimal age-replacement policy of a system subject to shocks with random lead-time," International Journal of Systems Science, vol. 159, no. 1, pp. 132-144.

[15] S.-H. Sheu, Z. G. Zhang, Y.-H. Chien, and T.-H. Huang, "Age replacement policy with lead-time for a system subject to non-homogeneous pure birth shocks," Applied Mathematical Modelling, vol. 37, no. 14-15, pp. 7717-7725, 2013.

[16] S.-H. Sheu, C.-C. Chang, and Y.-H. Chien, "Optimal agereplacement time with minimal repair based on cumulative repair-cost limit for a system subject to shocks," Annals of Operations Research, vol. 186, no. 1, pp. 317-329, 2011.

[17] M. J. Armstrong and D. R. Atkins, "Joint optimization of maintenance and inventory policies for a simple system," IIE Transactions, vol. 28, no. 5, pp. 415-424, 1996.

[18] M. J. Armstrong and D. A. Atkins, "A note on joint optimization of maintenance and inventory," Institute of Industrial Engineers (IIE). IIE Transactions, vol. 30, no. 2, pp. 143-149, 1998.

[19] Y. T. Park and J. Sun, "Optimum ordering policy for preventive age replacement," Journal of Systems Science and Systems Engineering, vol. 18, no. 3, pp. 283-291, 2009.

[20] L. Wang, J. Chu, and W. Mao, "A condition-based orderreplacement policy for a single-unit system," Applied Mathematical Modelling: Simulation and Computation for Engineering and Environmental Systems, vol. 32, no. 11, pp. 2274-2289, 2008.

[21] W. Wang, "An inspection model based on a three-stage failure process," Reliability Engineering \& System Safety, vol. 96, no. 7, pp. 838-848, 2011.

[22] W. Wang, F. Zhao, and R. Peng, "A preventive maintenance model with a two-level inspection policy based on a three-stage failure process," Reliability Engineering \& System Safety, vol. 121, pp. 207-220, 2014.

[23] H. Wang, W. Wang, and R. Peng, "A two-phase inspection model for a single component system with three-stage degradation," Reliability Engineering \& System Safety, vol. 158, pp. 31-40, 2017.

[24] R. Yang, F. Z. Zhaofei, J. Kang, H. Li, and H. Teng, "Inspection optimization model with imperfect maintenance based on a three-stage failure process," Eksploatacja i Niezawodnosc Maintenance and Reliability, vol. 17, no. 2, pp. 165-173, 2015.

[25] S. Ross, "Renewal theory and its applications," Introduction to Probability Models, pp. 409-479, 2014. 


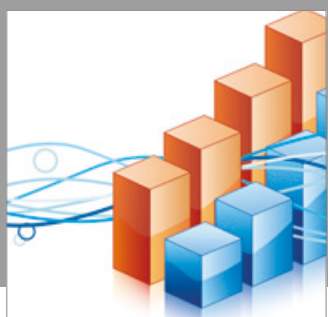

Advances in

Operations Research

vatersals

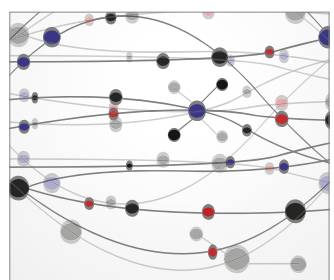

\section{The Scientific} World Journal
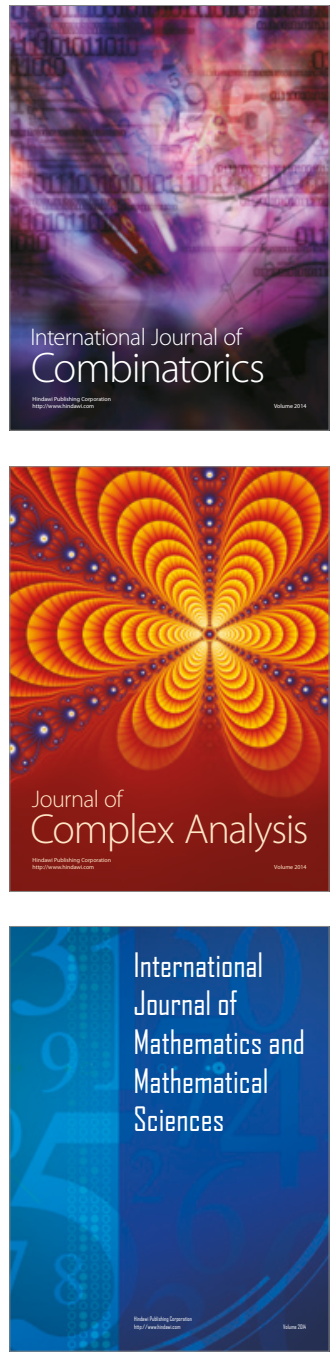
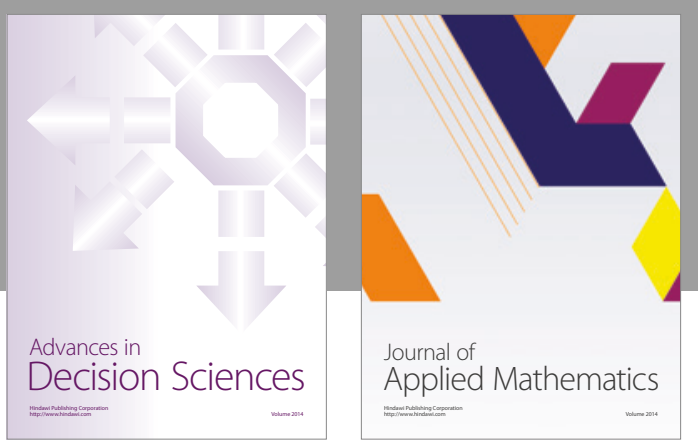

Algebra

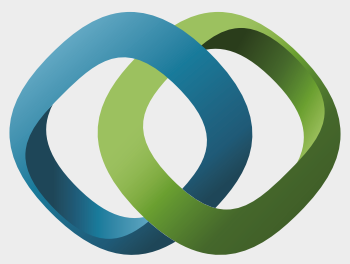

\section{Hindawi}

Submit your manuscripts at

https://www.hindawi.com
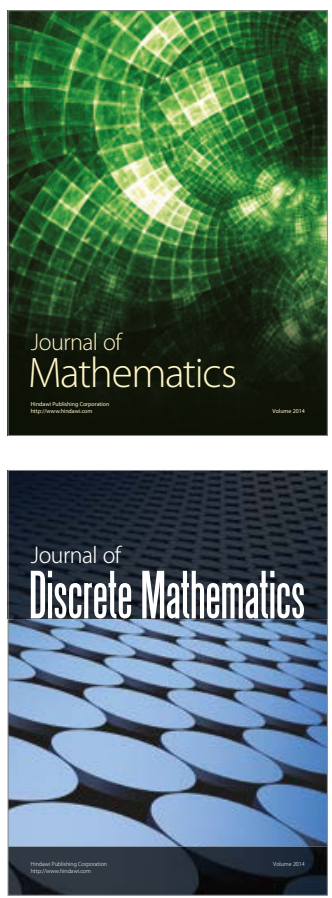

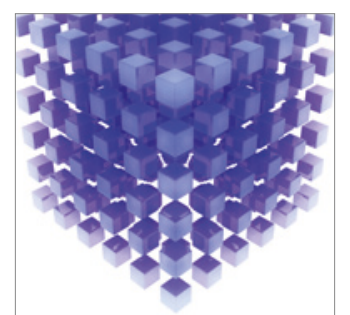

Mathematical Problems in Engineering
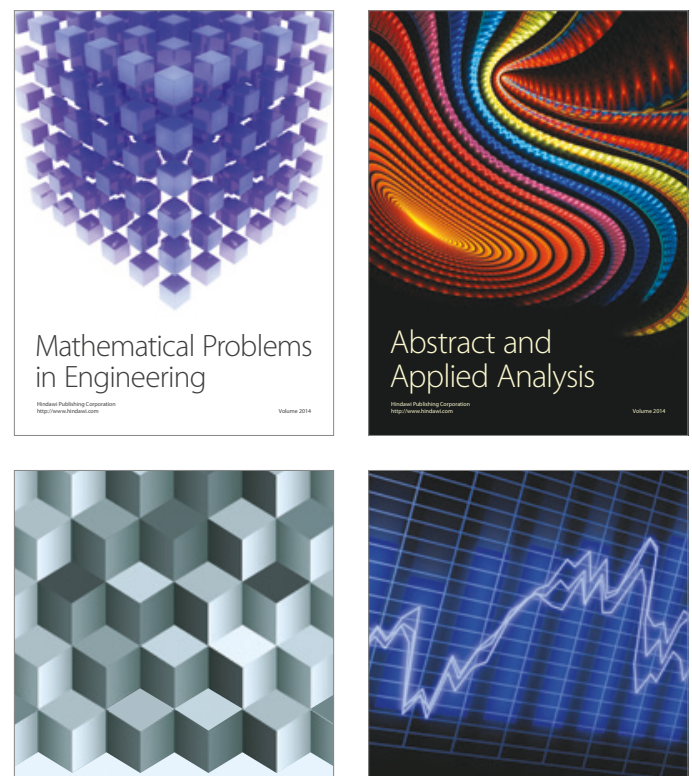

Journal of

Function Spaces

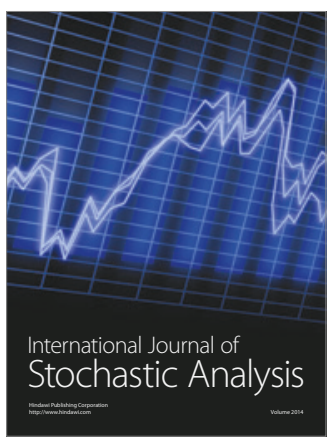

Probability and Statistics
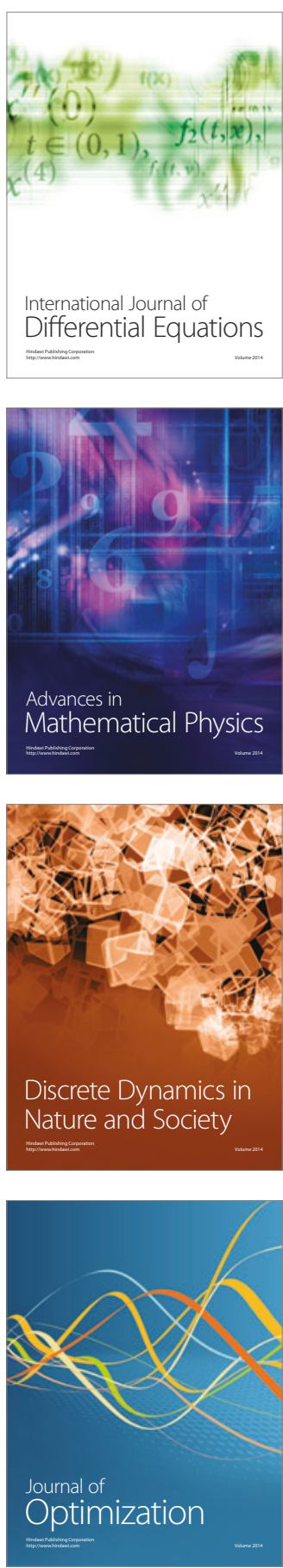